\title{
إدارة الأزمة لدى المدراء في وزارتي الدفاع والداخلية
}

أ ـ د ـ بثينة منصور الحّلو

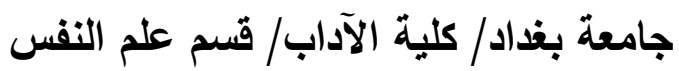

الباحثة: هبه حسين قاسم

جامعة بغداد/ كلية الآداب/ قسم علم النفس

\section{Hibahussein2@gmail.com}

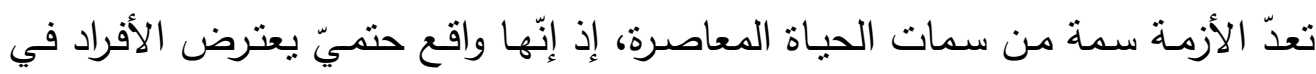

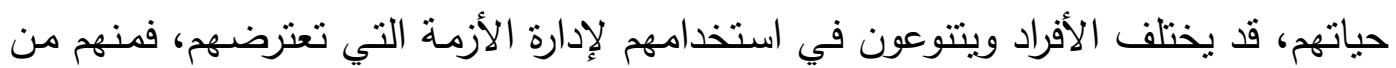

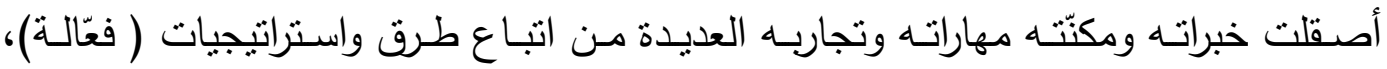

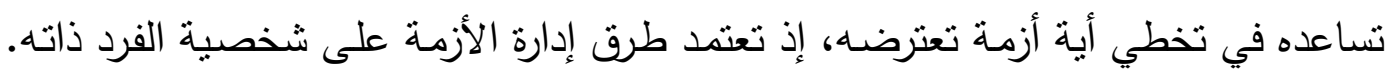

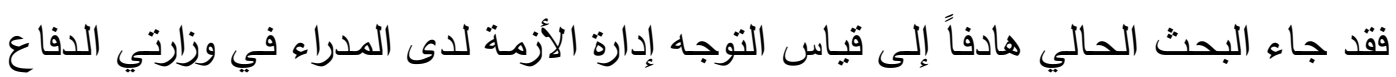
والداخلية ومعرفة أيّ الأساليب للتعامل في حل الأزمات.

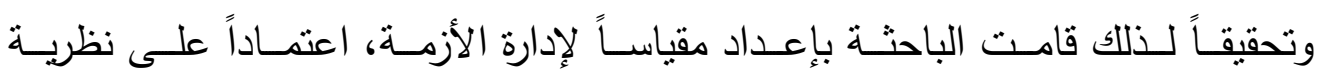

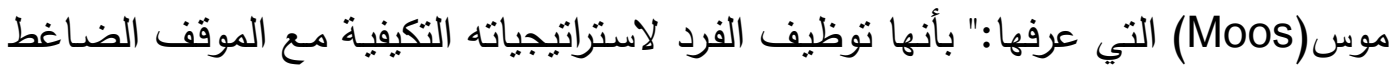

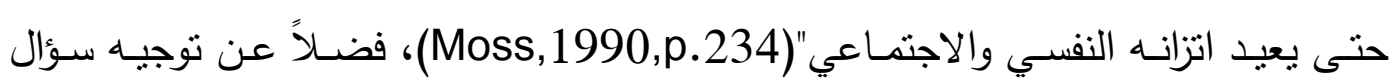
استطلاعي إلى العينة. وتم صياغة (18) موقفا يعبر عن الأزمة التي يمر بها المدراء في

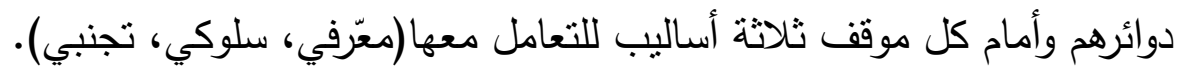

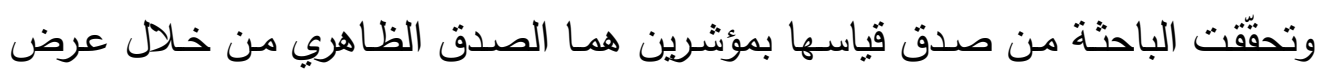
فقرات المقياس باستبانة على (14) محكماً في القياس النفسي وعلم النفس، وبناءً على آرائهم

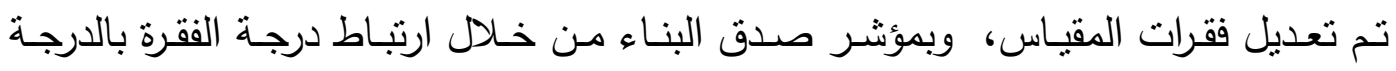

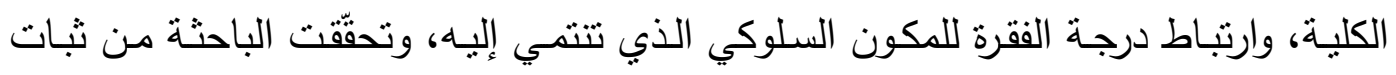

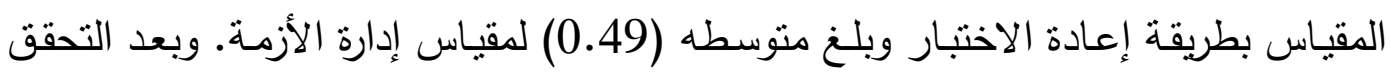

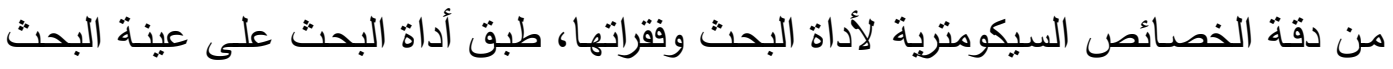

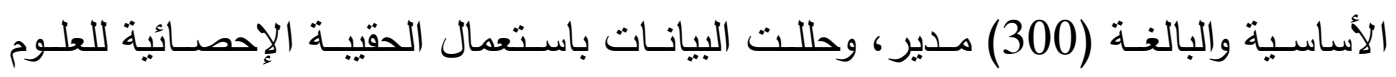
الاجتماعية(spss) وأظهرت النتائج مايأني:-

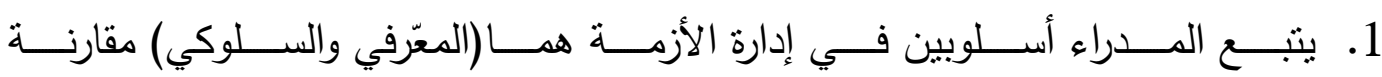
بالأسلوب(التجنبي). 2. يتبع المدراء الأسلوبين المعرفي والسلوكي في إدارة الأزمة. 
الفصل الأول

الإطار العام للبحث الاون

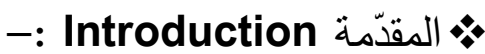

Problem Of The Research أولاً:- مشكلة البحثة

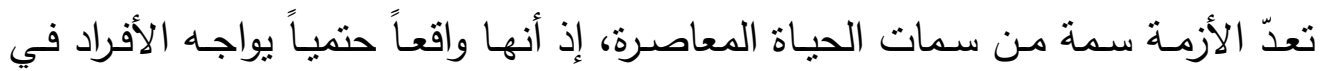

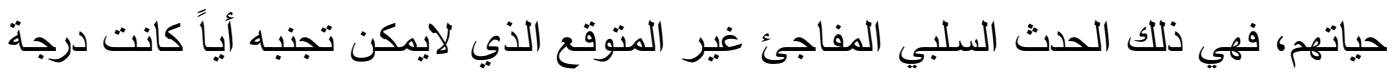

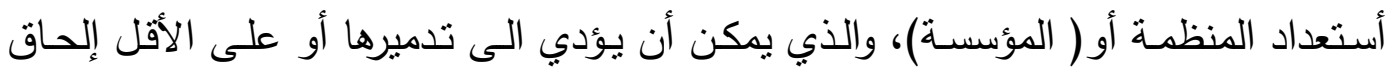

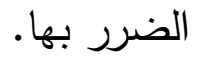

كما أسهمت التطورات الحديثة المتلاحِقة والتغير السريع في الأنظمة والقوانين وعدم الأستقرار فيها بالأضافة الى الظروف والأحداث الدفاجئة والسريعة، منها سباسية، أقتصادية،

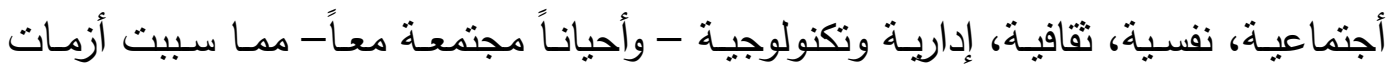
هددت مفاصل الحياة العامة والمؤسسات الإدارية، ومن ثم وضعت القيادات الإدارية أمام

$$
\text { تحديات كبيرة لإدارتها (عباس، }
$$

وسـاهمت تلك المسُببات بأن تُرهق الفرد وتتـتت تفكيرهُ وتصيبهُ بـالعجز عن الإدارة

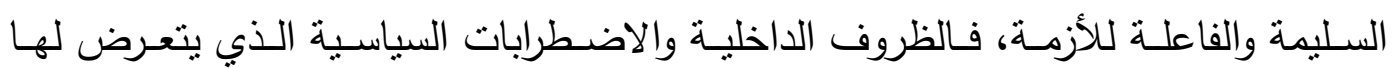

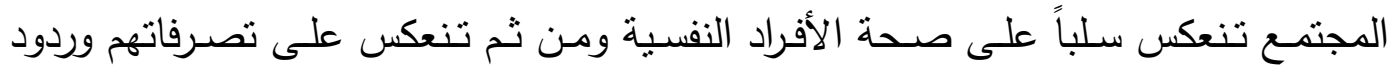

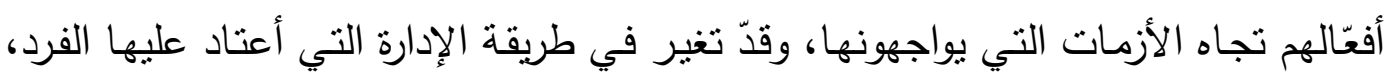

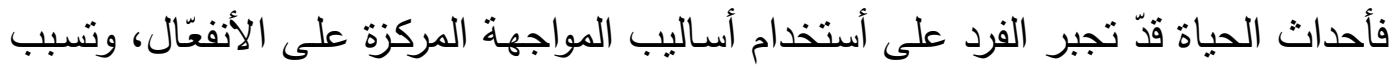

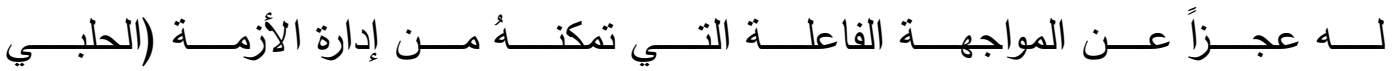

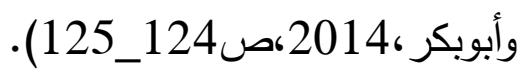
وقد بينت بعض الدراسات أن لثخصية المدير تأثير في إدارة المؤسسة ومن ثم الأزمات

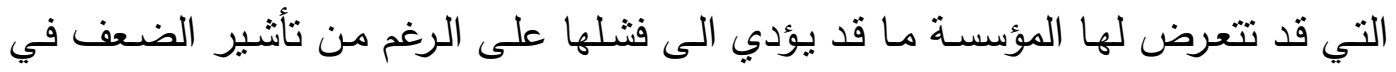

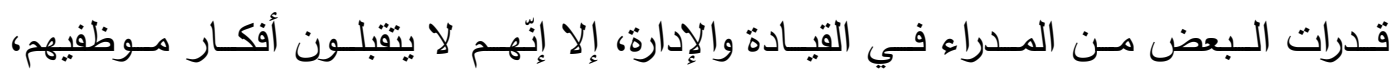

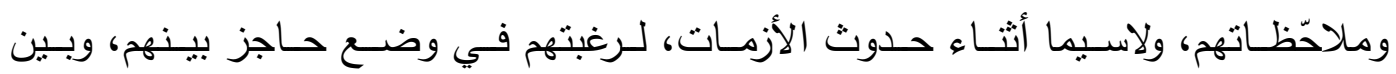

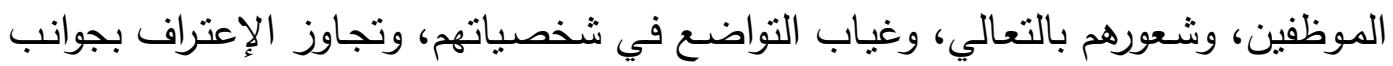

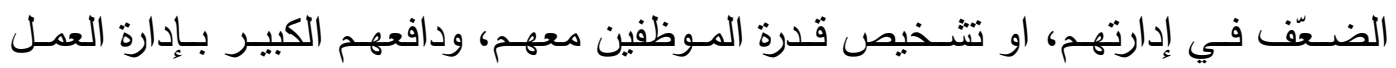
بطريقتهم، وأفكارهم، وليس بأفكار موظفيهم، وقدراتهم. فالمدير يعمد الى التسلط، والاستئنار

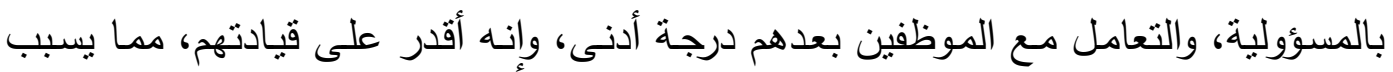

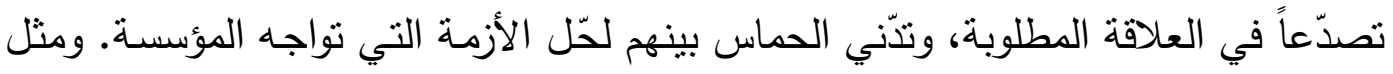
هذا النمط المتسلط للمدير كفيل بإكتساب عداوة الموظفين، ودفعهم الى مقاومة ما تصبو اليه 
الإدارة، ولاسيما في حالات التغيير الإداري (السلمي،1975،صلئ164). ولمواجهة الأزمات

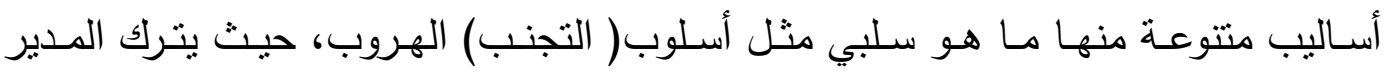

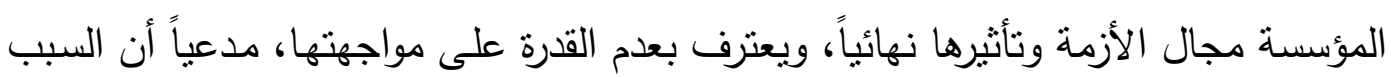

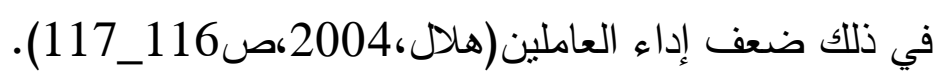
وتتحدد مشكلة البحث في الأجابة على التساؤل الآتي:

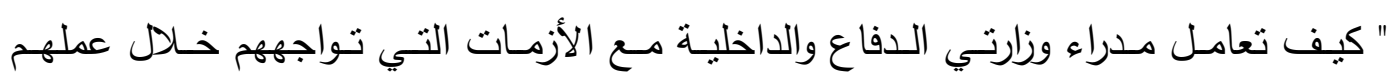
الإداري".

Significance Of The Research ثانياً: أهمية البحث

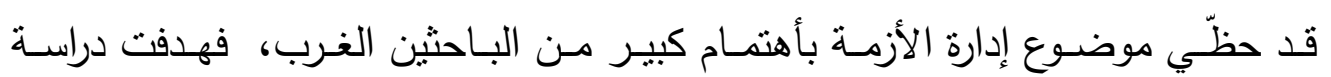

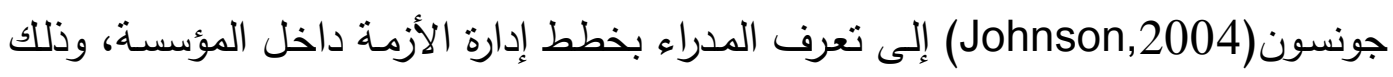
لمواجتها، وأثنتت دراسة إفيريت(Everett,1991) إن إدارة الأزمة في المؤسسات تكون من إنسات

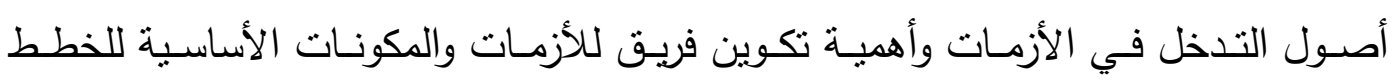

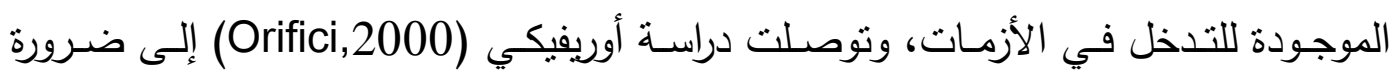

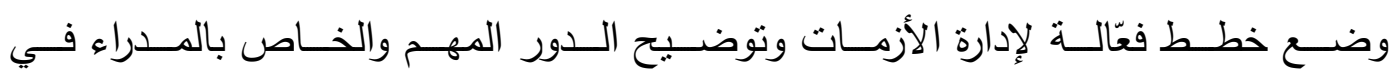

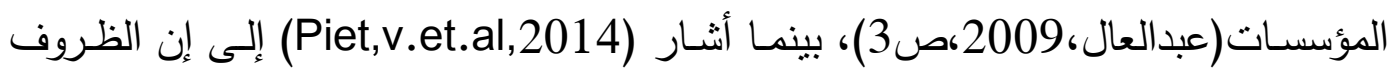

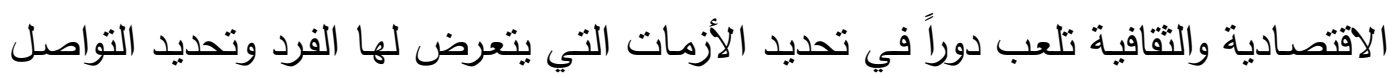

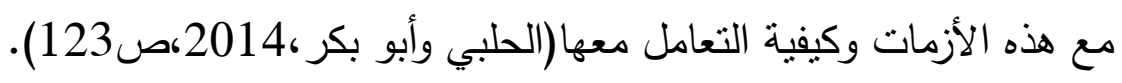

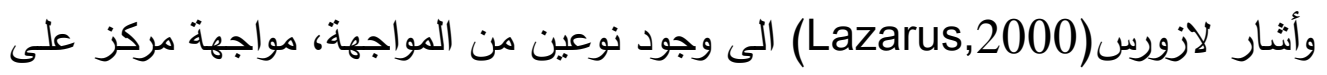

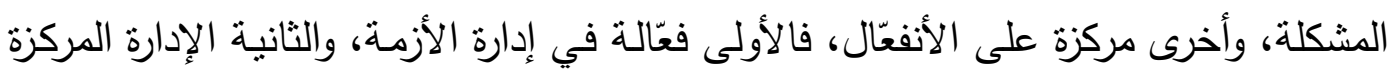

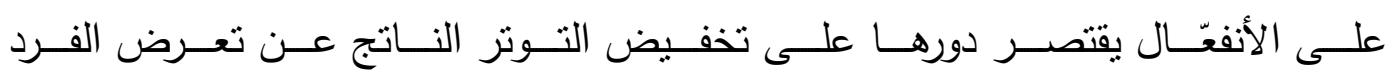
للأزمة(Lazarus,2000,p.665_673).

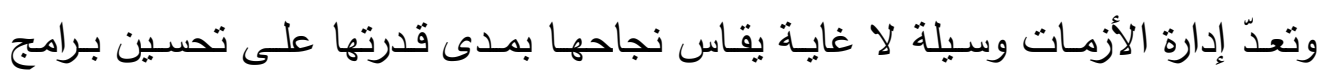

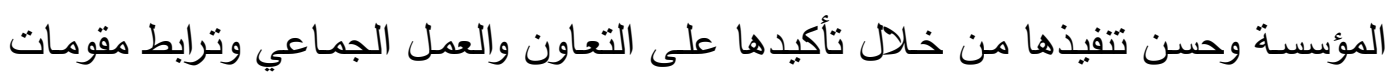
العملية الإدارية مع بعضها البعض وهذا يفرض على المدير أو القائد العسكري والأمني فهماً

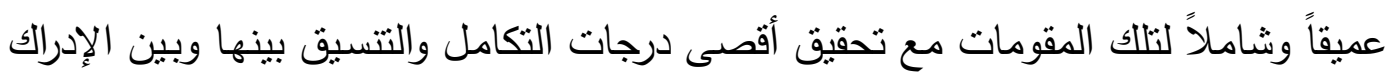

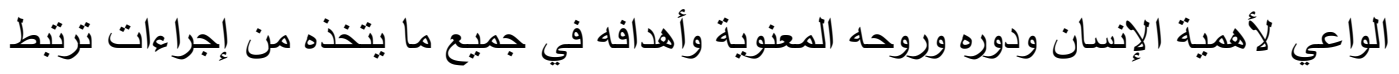

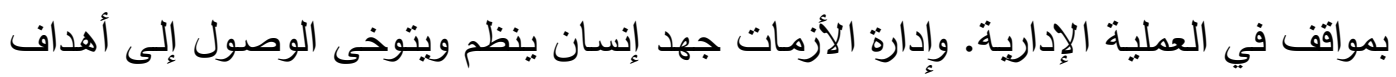

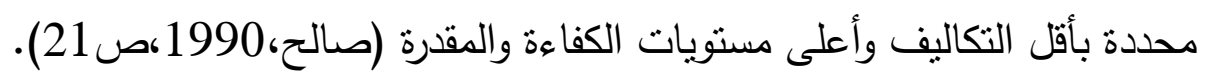

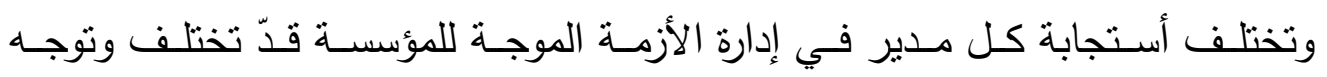

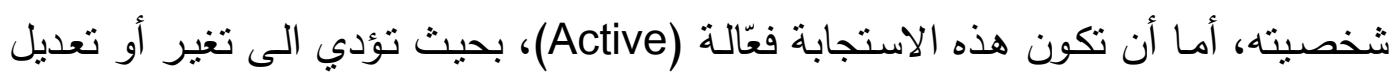


مسار الأزمة وصولاً الى درجة التوازن والتكيف التي تشعر المدير بالراحة، وهذه الأستجابة قدّ تكون معرّفية (Oognative) أو سلوكية (Behavorial) أو تكون أستجابة المدير لإدارة

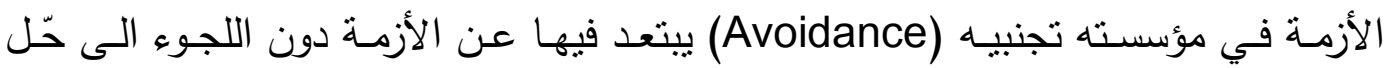
مايواجهه من أزمات (Holahan,1987,p.946).

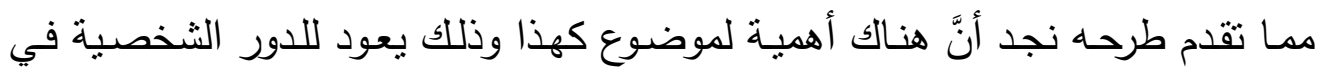

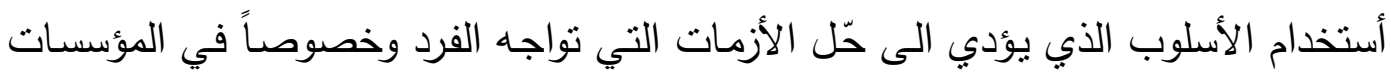

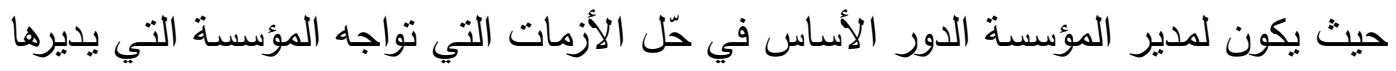
وبالتالي ما يؤدي الى نجاح هذِِ المؤسسة ونموها.

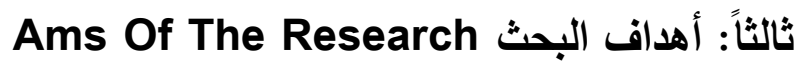
يستهدف البحث الحالي التعرّف على: 1. أساليب التعامل في إدارة الأزمة لدى المدراء في وزارتي الدفاع والداخلية.

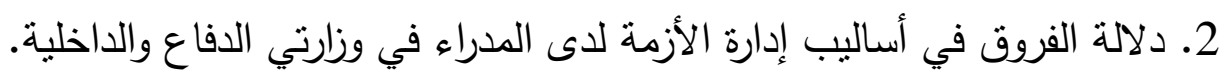
Limitsof The Research رابعاً: حدود البحث الحالي يتحدد البحث الحالي بمن هم بمنصب إلمالي مدير عام، ومعاون مدير عام، مدير دائرة

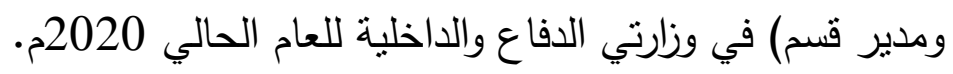
خامساً: تحديد المصطلحات Definition Of The Terms

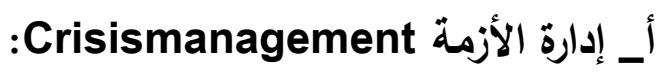
يعرفها هولهان وموس (Holahan \& Moos,1987):" جهود الفرد لتعلم تحمل التهديد الذي يؤدي الى الأزمة أو ضبطها ، أو خفضها"(Holahan \& Moos,1987,p.946).

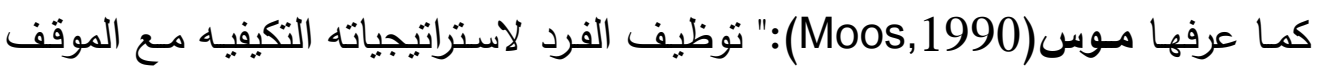
الضاغط حتى يعيد أتزانه النفسي والاجتماعي"(Moos, 1990,p.234).

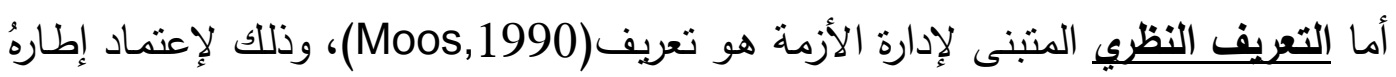

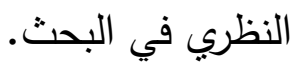
أما التعريفـ الاجرائي:" هي الدرجة التي يحصل عليها المستجيب جراء أختياره لأساليب التعامل( المعرفية، السلوكية أو التجنبية). ب_المدير The Master: وعّرفه(النعيمي، 2007):"وهو الموظف الذي ينولى مسؤولية إدارات ذات مهمات وظيفية

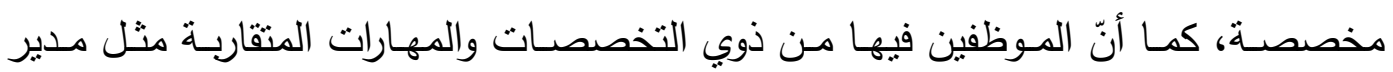

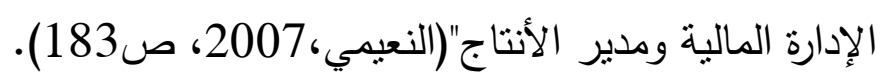


الفصل الثاني

الأدبيات لمفهوم البحث المثي

أ- الأزمة Crisis:

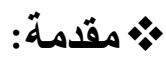

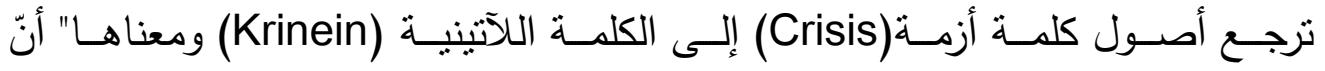

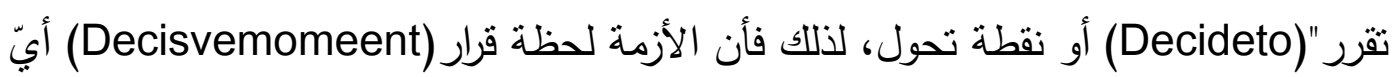

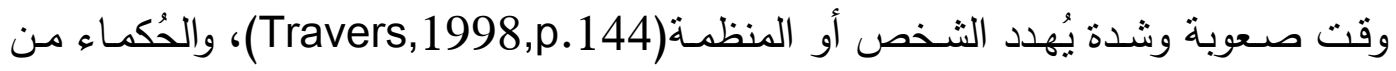
لات

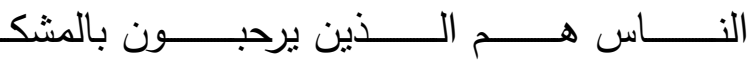
يرهبونها (مكاوي، 2005، صنان هند). • ب أسباب الأزمة على مستوى الأفراد والمؤسسات: وأرجع كل من( \&uklaa,1986 \& Champox, E .josephn, 2000 \& (Nitroof,2001

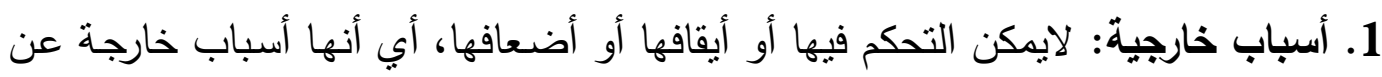

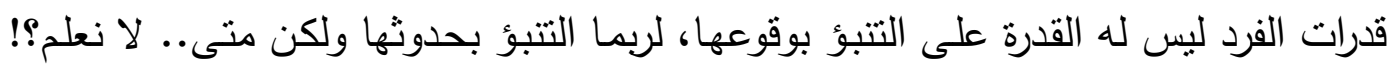

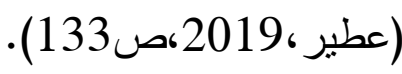
2. أسـباب داخليـة: أي تعود إلى الإنسـان مثل" سوء الفهم، سوء الإدراك، سوء التقدير

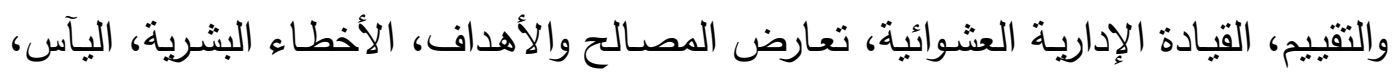

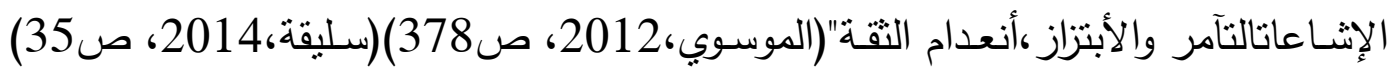
(Mitroff,1994,p.7)(Nitroof,2001,p.52)(Kuklaa,1986,p.39)

ب- بإرة الأزمة Crisis Management:

تعدّ إدارة الأزمة من الموضوعات الحيويـة التي لها تأثنير في حياة وبقاء المؤسسة، إذ إذاء

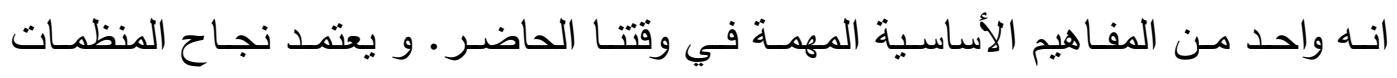

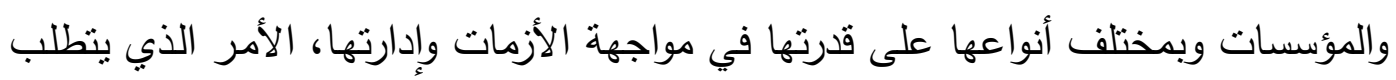

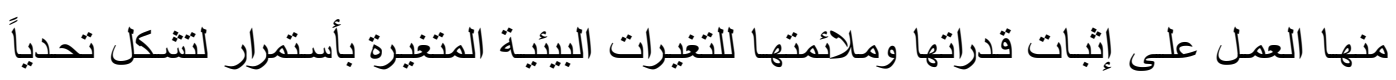

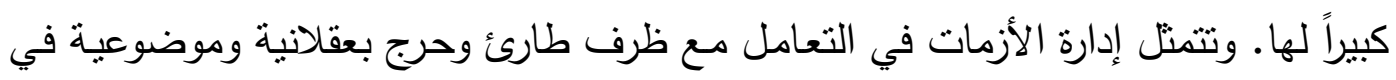

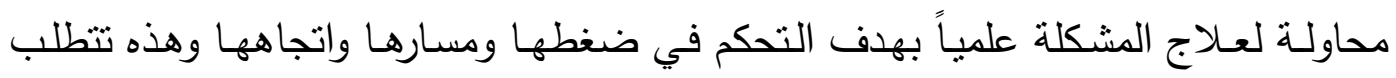

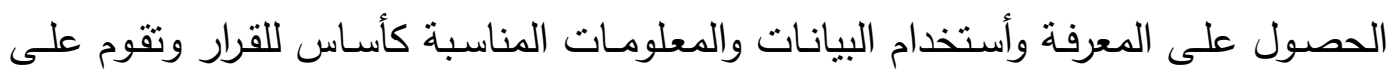

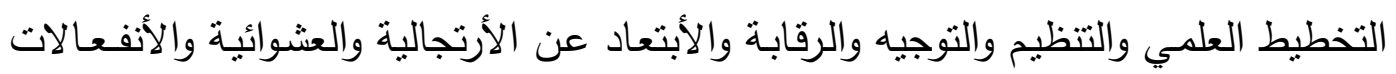
الوقتيـة. فقد تعددت الأراء حول مفهوم إدارة الأزمات مـن وجهـة نظر الكتاب والبـاحثين 
(المالكي،2009،ص30). وفي ضوء ما تقدم، يؤكد(Pattarson,1993) أنّ إدارة ألازمة تحقق للمنظمة فوائد كثيرة تتمنل بـ:

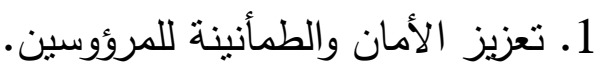
2. زيادة معرفة وشعور المرؤوسين. 3. زيادة الثقة والروح المعنوية داخل المؤسسة. 4.حماية وتعزيز سمعة المؤسسة وتخفيض القضايا القانونية(Pattarson,1993,p.98). ويخلط بعض متخذي القرار بين مفهوم إدارة الأزمات (Crisis Management) ومفهوم الإدارة بالأزمات(Management by Crisis) والإدارة بالأستثناء، فعملية إدارة الأزمات هي كيفية التغلب على الأزمة بالادوات العلمية الإدارية المختلفة وتجنب سلبياتها

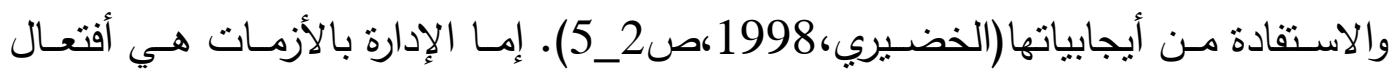

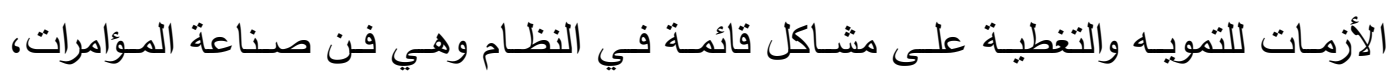

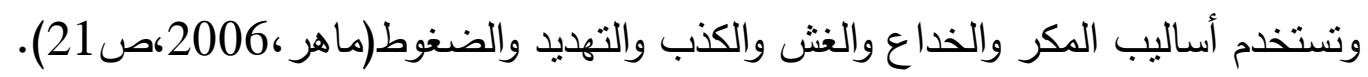

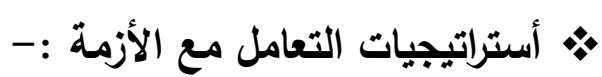

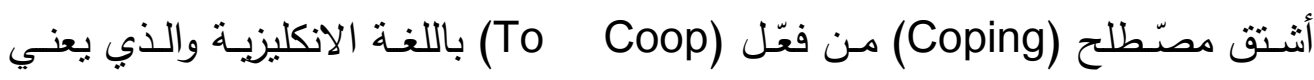

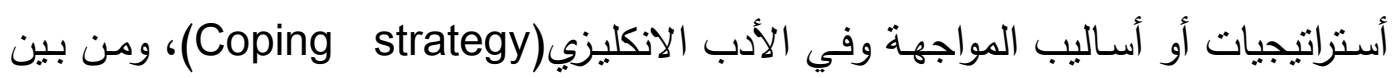

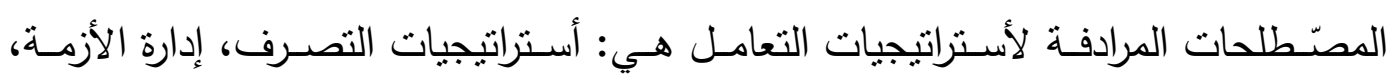

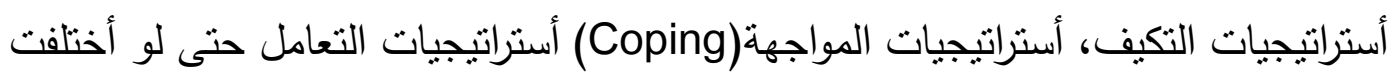

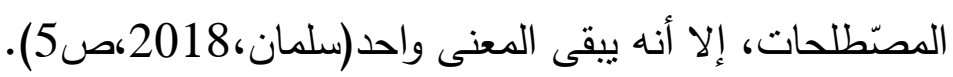

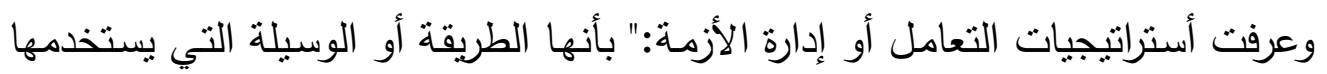

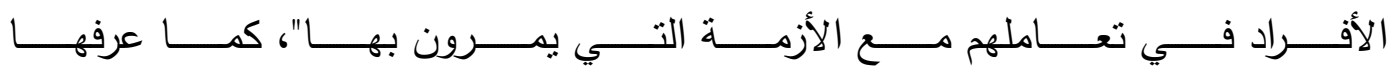
سبيلبرجر (Spielberger,1979):" بأنَّا عملية وظيفتها خفض أو أبعاد المنبه الذي يدركهُ

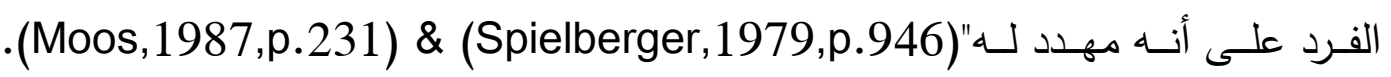

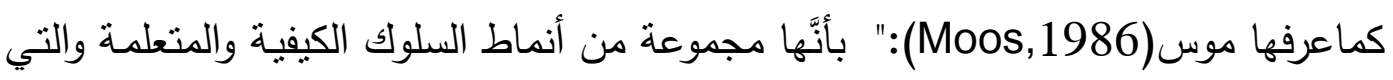
تتطلب عادة بذل الجها، وتحددها الحاجة، وتستهدف حّل الأزمات، كما يمكن السيطرة عليها

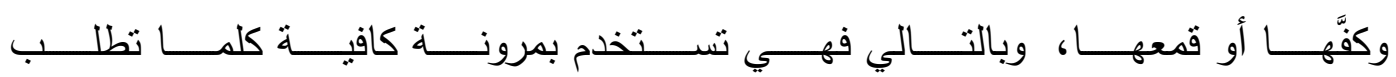
الموقف"(Moos,1986,p.13). ويمكن استخدام أسـاليب أو استراتيجيات مختلفة لإدارة

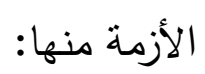
أولاً- الاستراتيجيات الإيجابية: وهي تلك التي يوظفها الفرد في اقتحام الأزمة وتجاوز أثنارها.

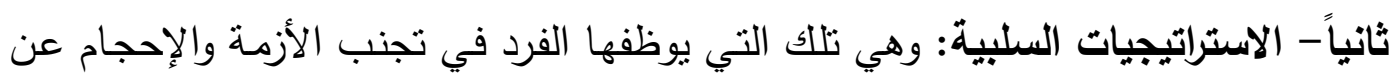
التفكير فيها. 
ورأى العَّالمان لازاروس وفولكمان(lazarus \& folkman):" أنّ لعملية إدارة الأزمـة

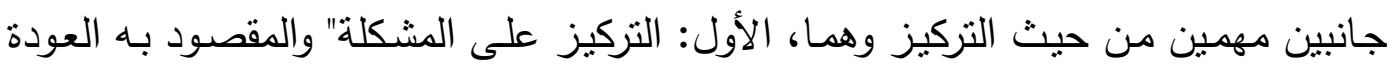
الى الجهود من أجل تحسين العلاقة السلبية بين الفرد وبيئته عن طريق التغيير من خلال

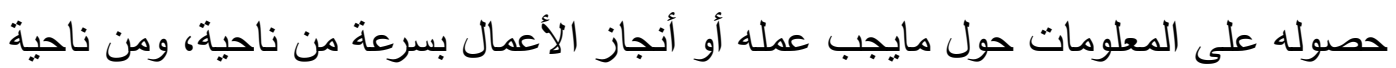

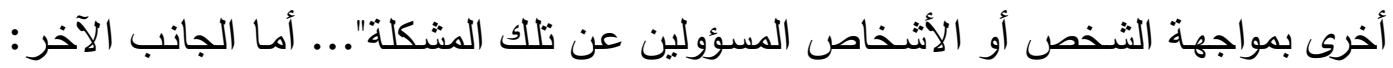

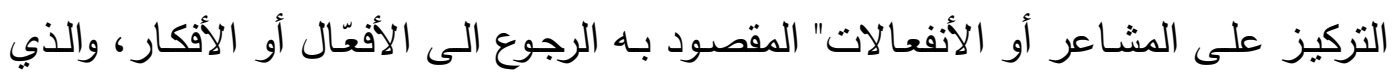
يهدف الفرد من خلالها الى التخفيف من تأثير الأزمات عليه"(folkman, 1997,p.207).

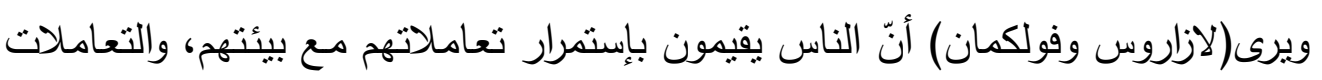

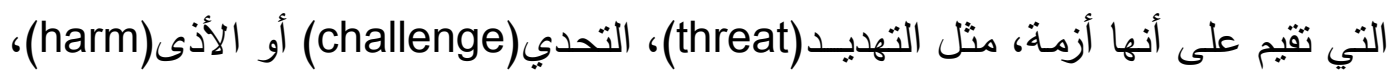

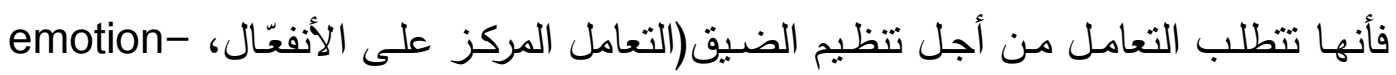

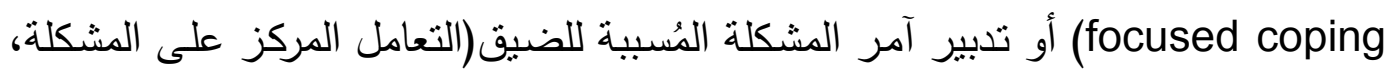

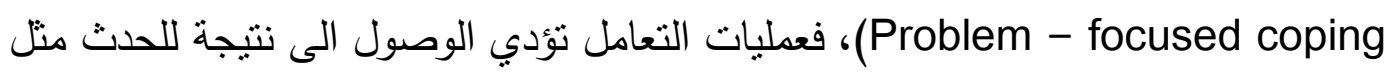

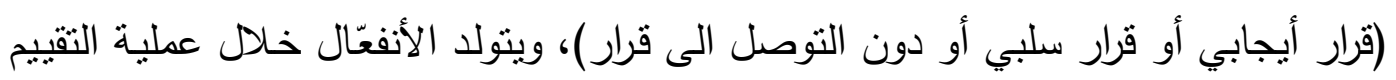

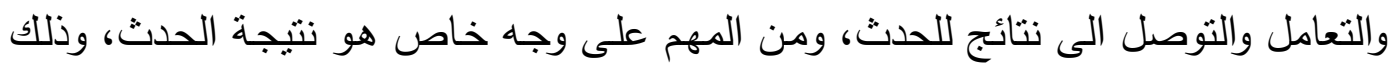
لان النتيجة الايجابية يحتمل ان تؤدي الى أنفعال ايجابي وإنهاء فعالية التعامل، أما النها النتائج

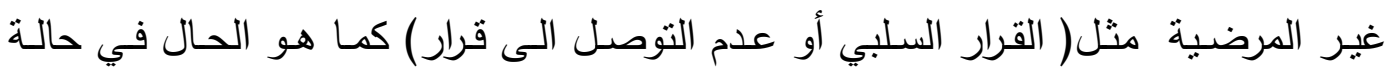

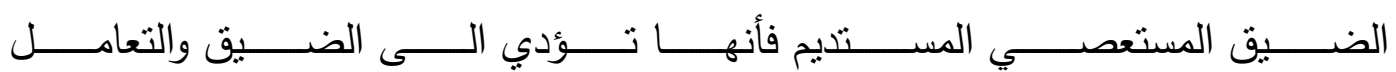

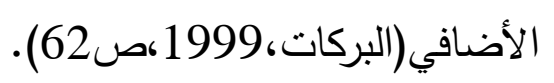
أولاً: الطرق التقليدية للتعامل مع الأزمات: تتسم هذه الأساليب بالسلبية والجمود وهي أبعد ما تكون عن الإدارة التي هي بمثابة التمابة

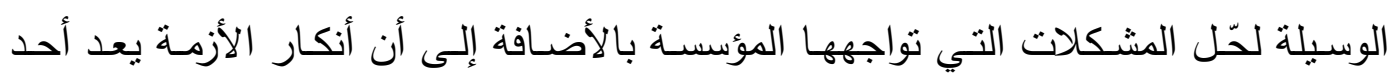
الأخطاء التي ترتكبها المؤسسات في إدارة الأزمات(Kreitner,1989,p.18). وهناك الكاتك الكثير

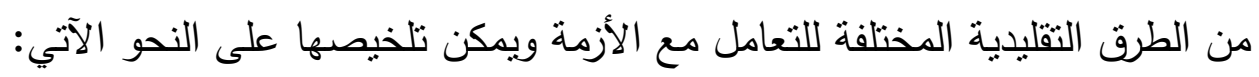

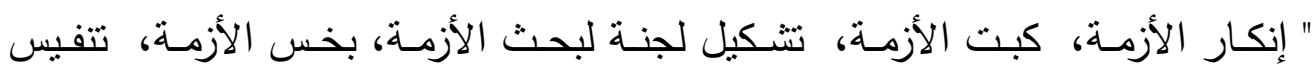

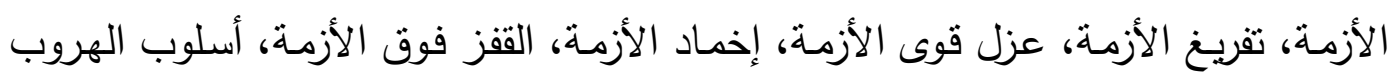
والتجنب(Escape-Avoidance)" (Fink,1986,p.80). ثانياً: الطرق الحديثة للتعامل مع الأزمة:

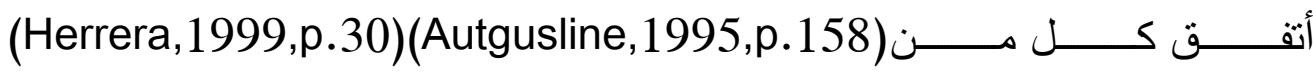

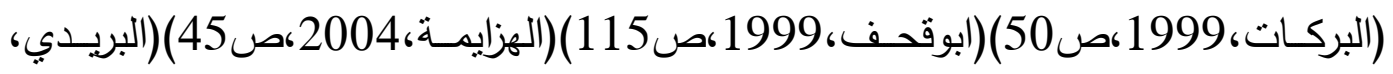
1999،ص6)... على أنّ هناك ست مراحل لإدارة الأزمة هي: 
"منع حدوث الأزمة، الاعداد لإدارة الأزمة، أدراك والأعتراف بالأزمة، احتواء الأزمهة،

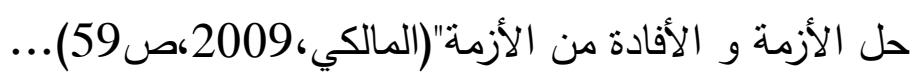

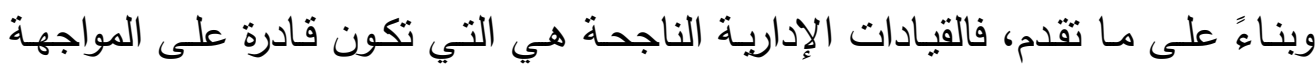

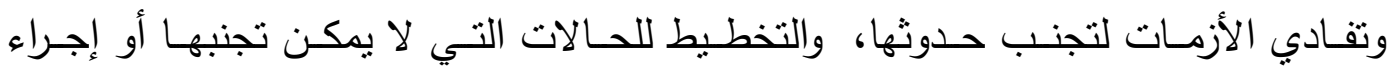

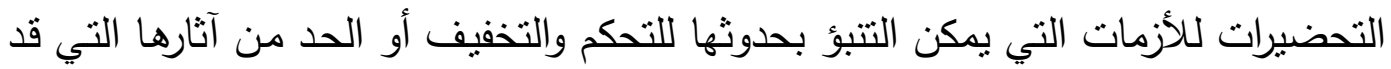
تكون تدميرية في بعض الأحيان والى التقليل من التكلفة الاقتصادية للمواجهة والحد من آثار الوقت الضائع والمهدور والتخفيف من عنصر المفاجأة.

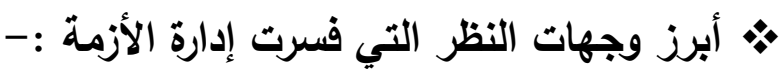

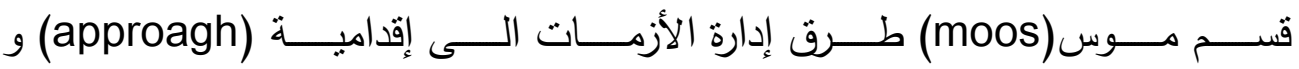
أحجامية(avoidance)، وأن للاستراتيجيات الأقدامية والأحجامية جانبان: أحدهما معرفي الأني

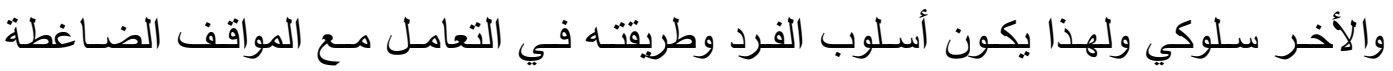

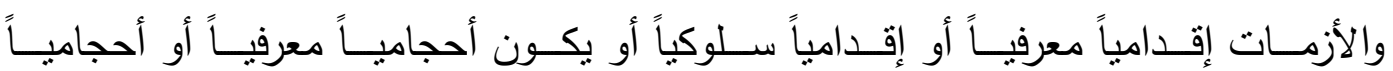

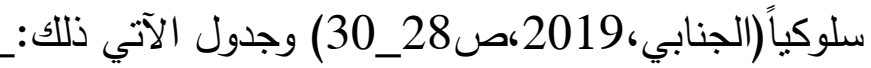

\begin{tabular}{|c|c|c|}
\hline الإساليب الإحجامية & الاساليب الإقدامية & $ت$ \\
\hline الإحجام المعرفي & التحليل المنطقي & 1 \\
\hline التقبل الإستسلامي & إعادة التقييم الايجابي & 2 \\
\hline البحث عن الاجابات البديلة & البحث عن المساعدة والمعلومات & 3 \\
\hline التنفيس الأنفعالي & حل المشكلة & 4 \\
\hline
\end{tabular}

(moos,1988,p.133)

ويرى موس(moos) إن ذلك لله علاقة بالصحة الجسمية والتوافق النفسي ودورها في عمليـة تقدير الفرد المعّرفي للأزمـة وكيفيـة وصـوله الى مغزى الحدث والمهيـات التوافقيـة

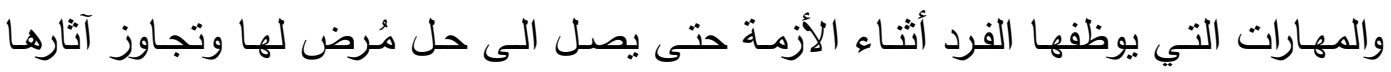
الضارة فبمجرد تلقي الفرد الموقف الضاغط والمرور به يبدأ بأدراك الأزمة والثروع في تحديد

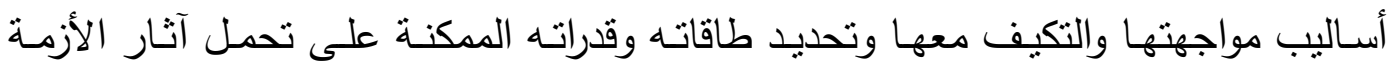

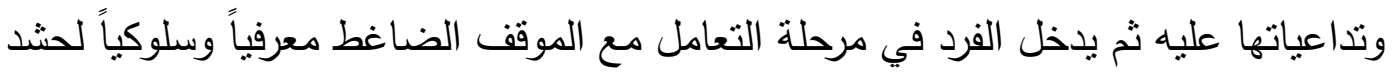

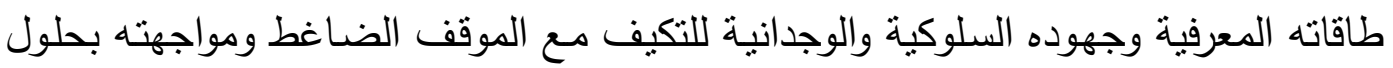
ايجابية كما تتضح نتائج الموقف وآثاره على الفرد، اذ يتضح فيها مدى التفاعل بين مكونات

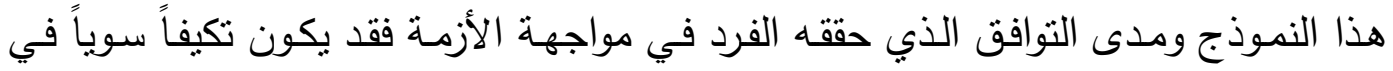

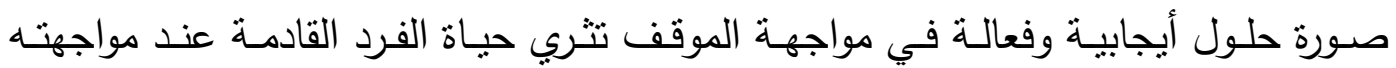

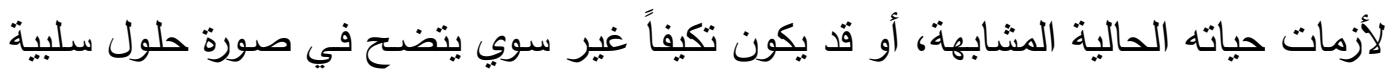


أنسحابية تؤثر في حالته فتظهر عليه الأعراض الاضطرابية والتوترات التي تؤثز سلبياً في صـته الجسمية والنفسية كمـا انها تتـزر بفتـله في التوافق مـع الأزمات التاليـة في حياته المستقبلية وتحولاتها غير المتوقعة (moos \& et al ,1992,p.102). الفصل الثالث منهجية البحث واجراءاته ثم مجمع البحث

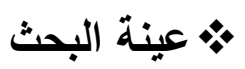

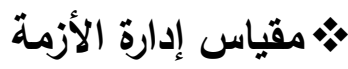

تحقيقاً لأهداف البحث، أستوجب تحديد منهجه ومجتمعهد وأختبار عينته و أداة البحث المناسبة التي تتصنّف بالصّّدق والثبات فضـاً عن تحديد أهم الوسائل الإحصـائية لتحليل البيانات ومعالجتها، وعلى النحو الآتي:

أولاً: منهجية البحث Research Method أستخدم في البحث الحالي الدنهج الوصفي(Description Research)، كونـهُ أسلوباً

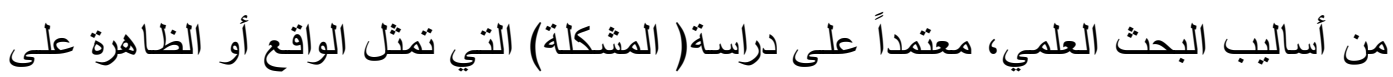

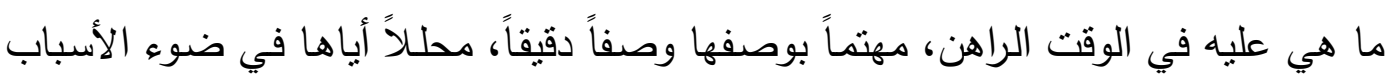

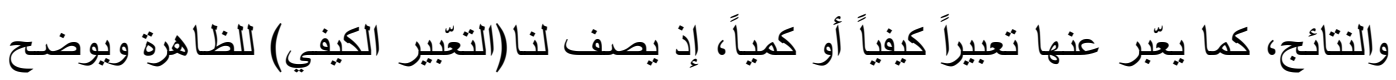

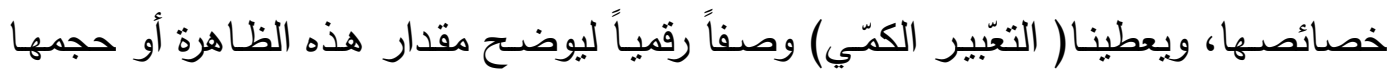

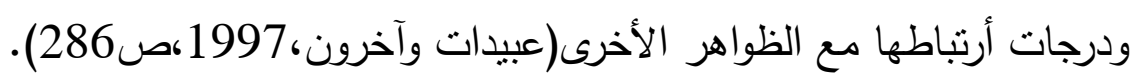

ثانياً: مجتمع البحث Population of the Research يتحدد مجتمع البحث الحالي بالمدراء( مدير عام، مدير دائرة ومعاونيهم، رئيس قسم) لسنة 2020 في الدوائر والمديريات التابعة لوزارتي الدفاع والداخلية والبالغ عددهم (300) لدائرة مديراً.

Sample of the Research ثالثاً: عينة البحث

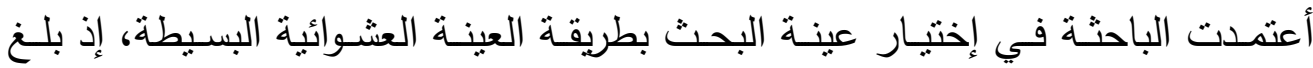

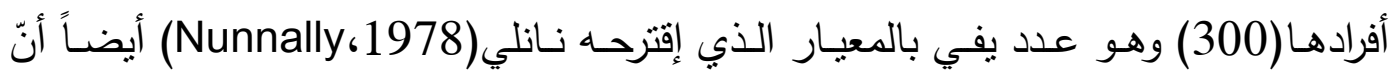

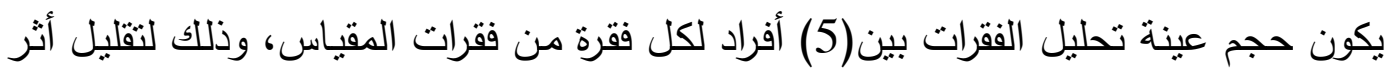

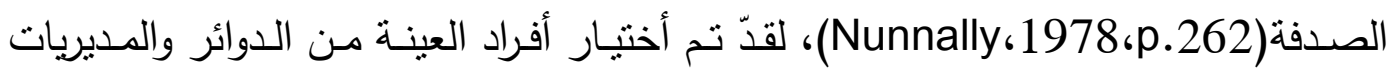
والمؤسسات التابعة لوزارتي الدفاع والداخلية. 
Scales of the Research رابعاً: أداة البحث

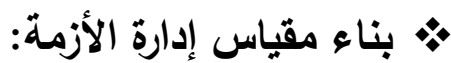

لغرض بناء مقياس إدارة الأزمة يلائم خصائص عينة البحث، فقّ تم الأطلاع على عدد

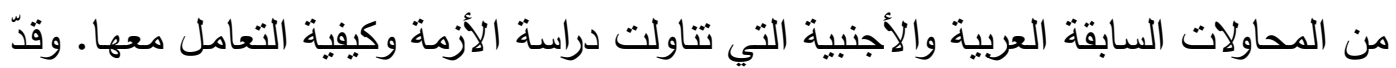
أكدت معظم البحوث في بناء المقاييس لتحديد الأزمات وأساليب التعامل معها أنَّ بطرح

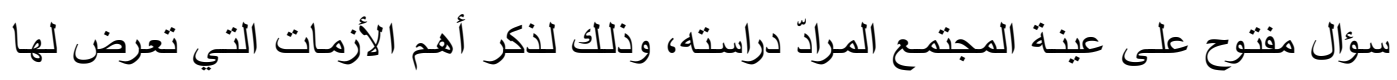
المفحوصون خلال حياتهم العملية وكيفية تعاملهم مع هذه علئه الأزمات.

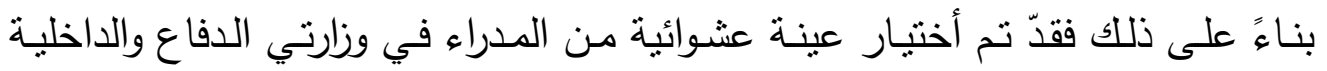

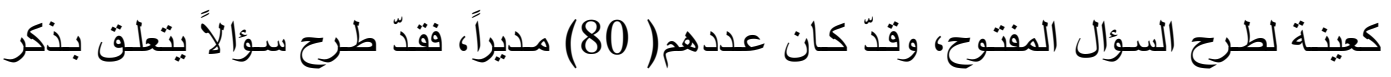
الأزمات التي تعرضوا لها خلال سنوات عمهم الماضية وكيف تم التعامل مع هذه الأزمات.

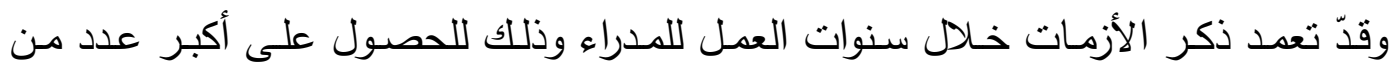
الاستجابات المكن الحصول عليها. تلت هذه الخطوة تحديد المواقف المتتشابهة وغير المتتـابهة لبناء مقياس إدارة الأزمة،

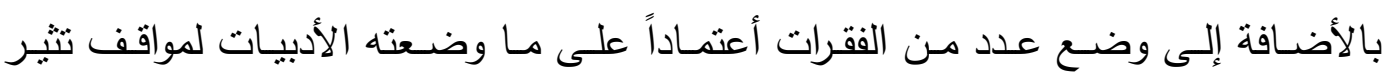

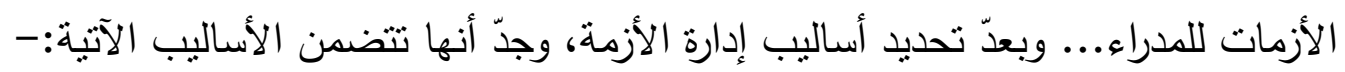

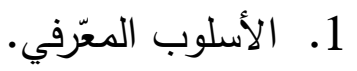

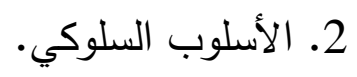

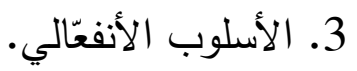

وقّ صيخ (18) موقفاً يمتل أزمات مفترضة في ذهن المستجيب، ليقرر نوع التعامل من

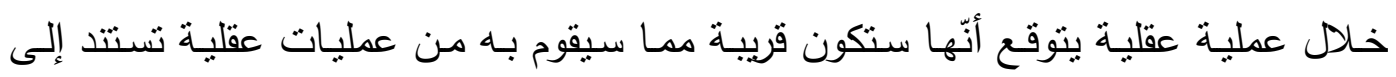
مخزونه المعرفي لوّ أنّه جوبه بأزمة كهذه لئه

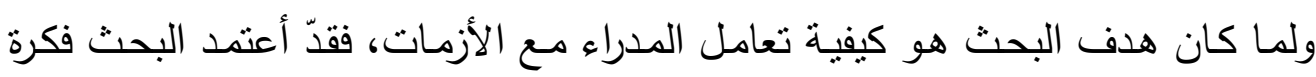
تصنيف أساليب التعامل مـع الأزمات، وقدّ عرض موس(Moos,1988,p.133) أساليب

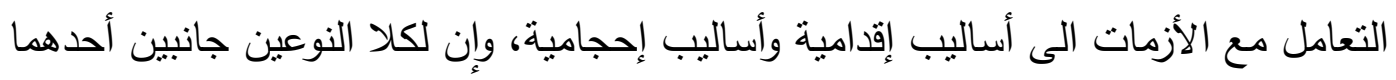

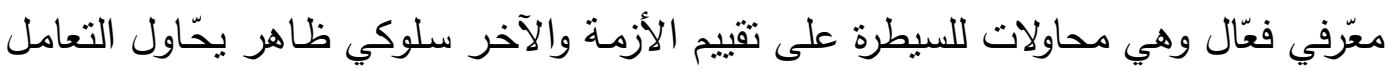

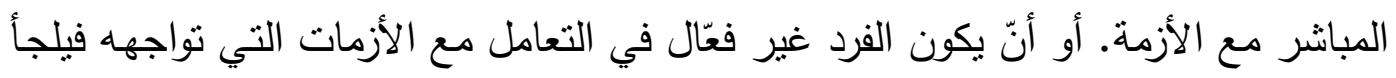

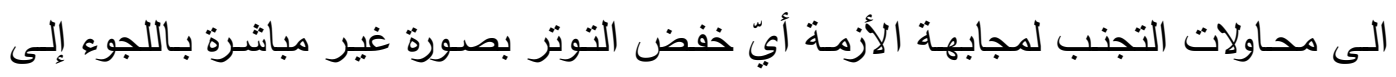

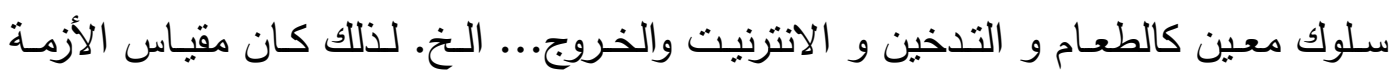

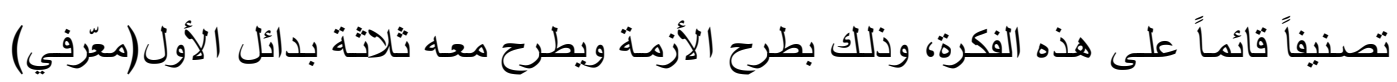
والثاني سلوكــــي( الفعّال) إما البديل الثالث فكان تجنيباً (غير فعّال). 
قدَّ نم طرح الأزمة ومعها ثنلاثة حلول، وعلى المستجيب أنّ يختار حلاً واحداً هو الأكثر

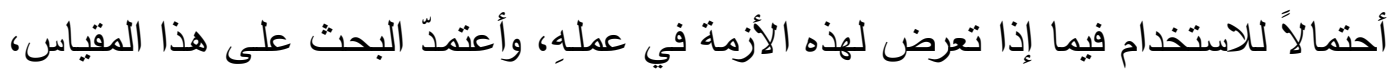

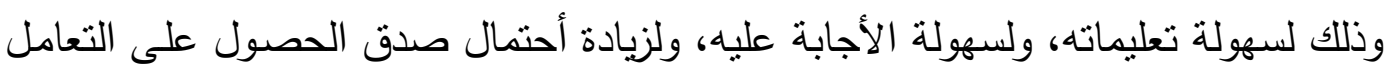

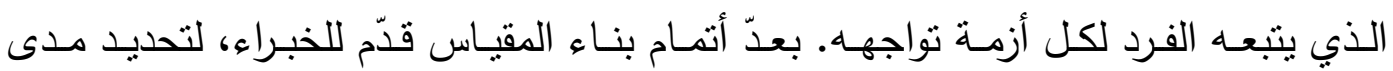

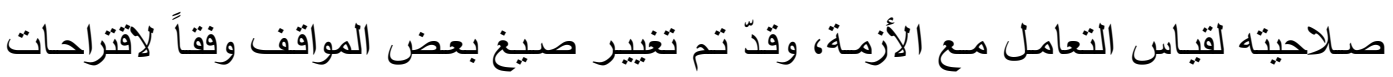
الخبراء.

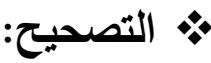

أنثتنمل مقياس إدارة الأزمـة على ( 18) موقفاً وتطرحّ مـعِ كل موقف ثلاثتة أسـاليب

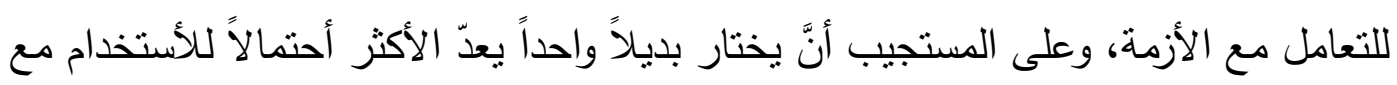

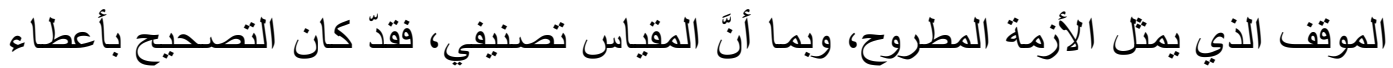
درجة واحدة (1) لكل بديل مختار لتشير الى مدى قوة أسلوب التعامل هذا. وبذلك تكون التهني

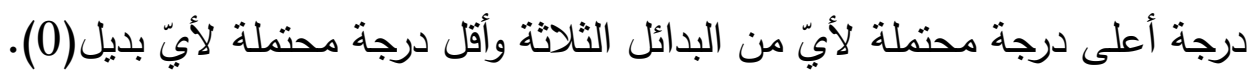

Psychometric Properties of the الخصسائص( السيكومترية) Scale

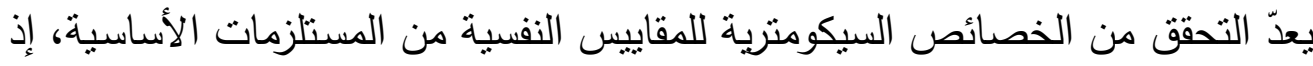

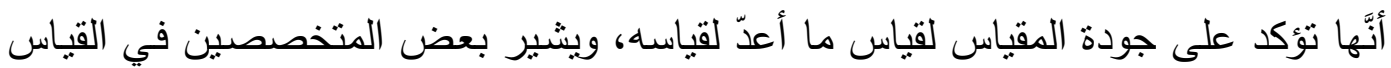

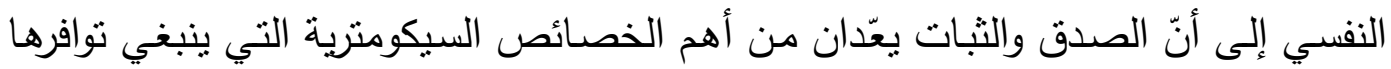

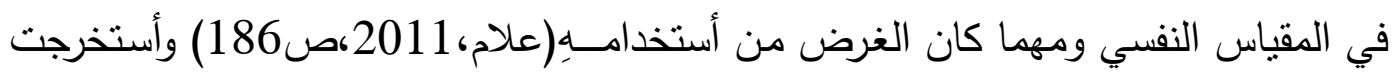
الباحثة صدق المقياس وثناته على وفق الإجراءات الآتية:

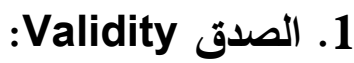

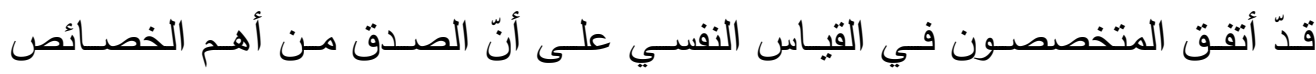

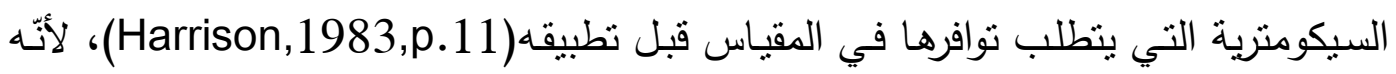

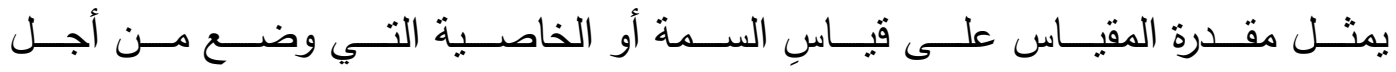

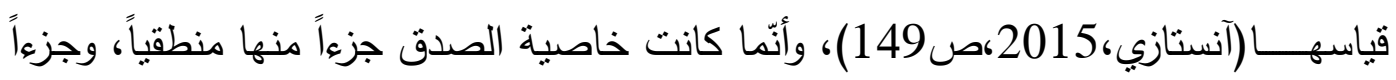

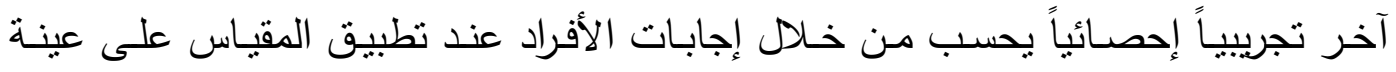

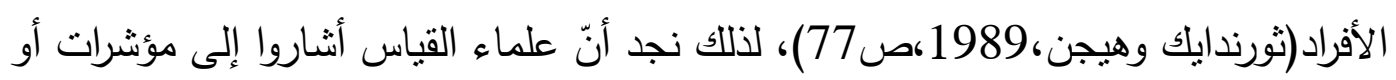

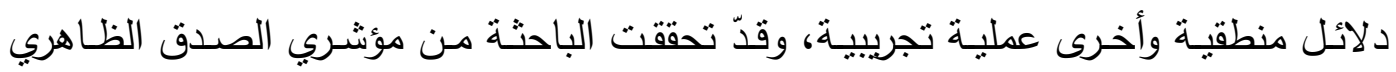
وصدق البناء للمقياس من خلال: 
أ- الصدق الظاهري Face Validity:

أفضل وسيلة لأستخراج الصدق الظاهري هي تقدير عدد من الخبراء والمختصين مدى

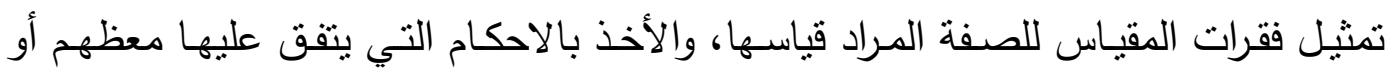

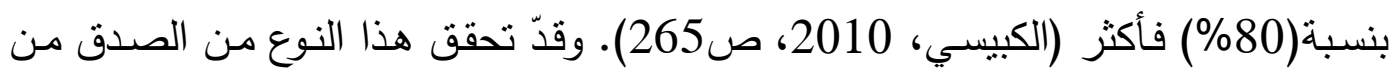

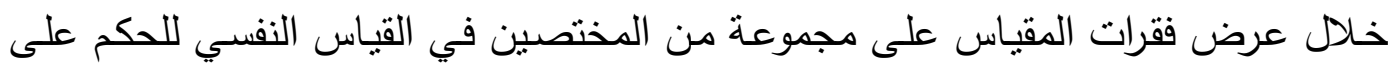

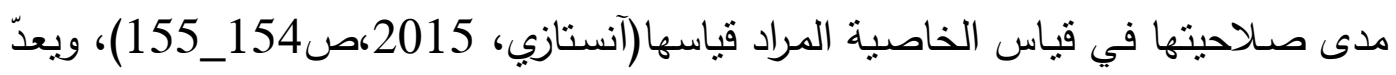

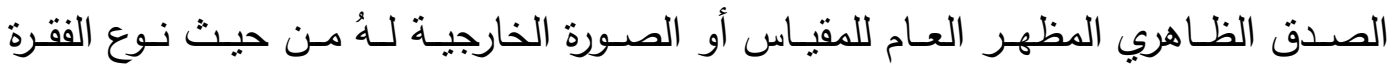

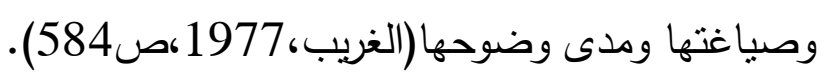

ب- صدق البناء Constract Validity:

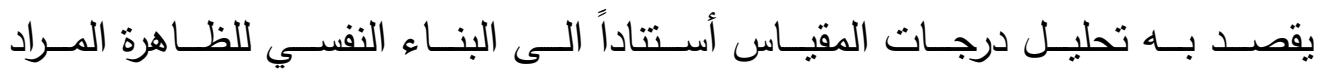
قياسهـا(Stanley \& Hopkins,1972,p.111)، وهو الددى الذب يمكن أنّ يقرر بموجبهـ أنّ المقياس يقيس خاصية معينة(Anastasi,1988,p.151) ويسمى أحياناً بصدق المفهوم

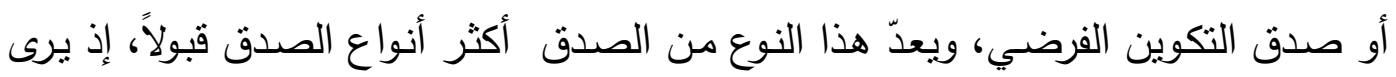

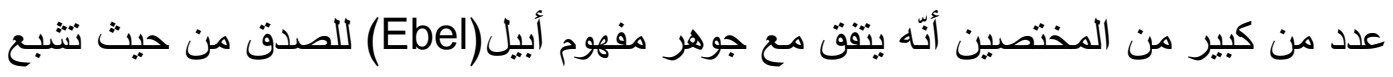

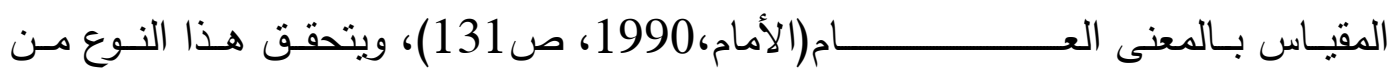
الصدق، حِينما يكون معيّار نقرر على أساسِهِ أنّ المقياس يقيس بناءً نظرياً محدداً. وجدول الآتي يوضح ذلك.

\section{2. الثبات Reliability:}

إذا كان الثبات يعني دقة المقياس، وأنّه يعرف إحصـائياً بنسبة التباين الحقيقي إلى

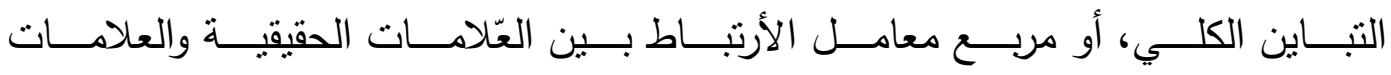

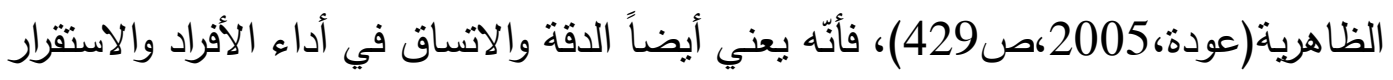

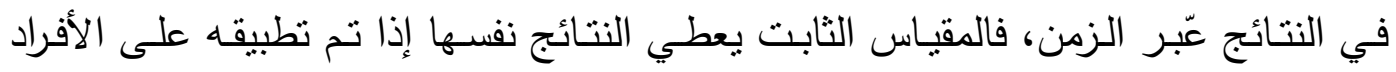
أنفسهم مرة ثانية(Barron,1981,p.418).

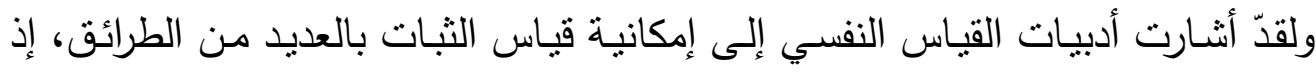

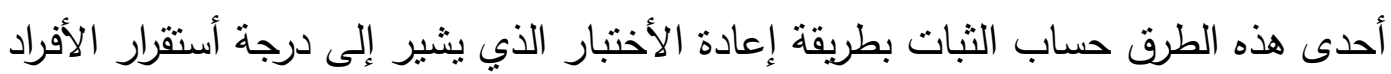

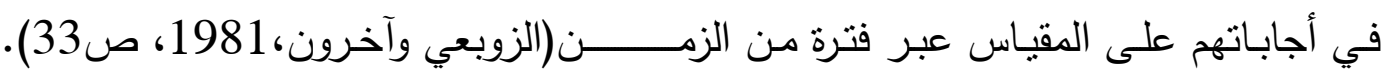

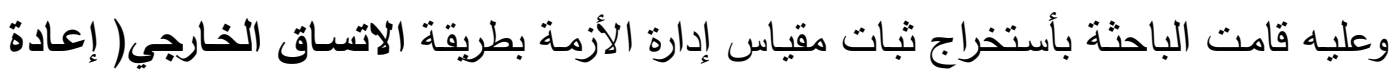
الأختبار (Test_Retest):-

تتضمن هذه الطريقة تطبيق المقياس على عينـة ممنلة من الأفراد، ثم إعادة تطبيق

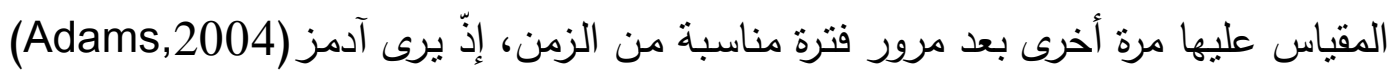




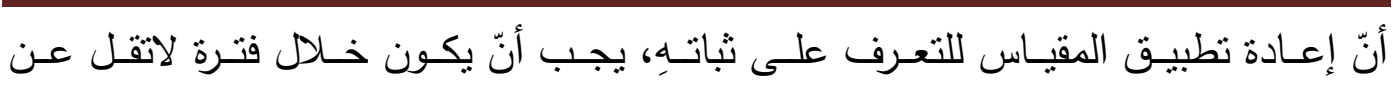

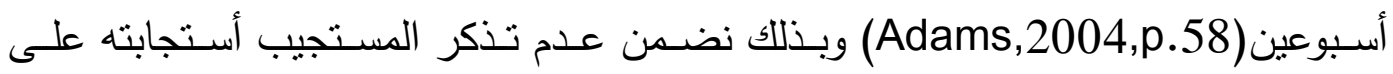
المقياس وأيضاً للحفاظ على الخاصية النفسية للمستجيب. وقدّ تم تطبيق مقياس إدارة الأزمـة لإستخراج الثبات بهذه الطريقة على عينةِ مكونـة من(15) مديراً من وزارتي الدفاع والداخلية، وبعد مرور أسبوعين من التطبيق الأول للمقياس تم بإعادة تطبيق المقياس ذاته مرة أخرى وعلى العينة نفسها، وبعد أستعمال معامل أرتباط بيرسون(Person Correlation Coffcient) للتعرف على طبيعة العلاقة بين درجات

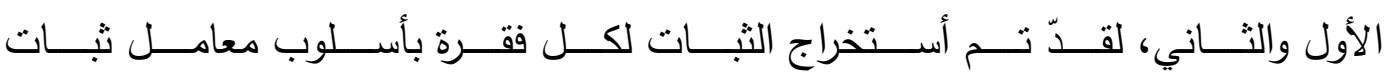
هولستي (") (Holisti,1969) المستخدم للمقاييس التصنيفية (Holisti,1969,p.12) لسهولة

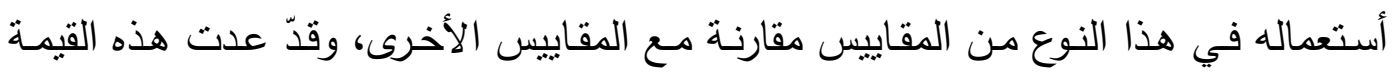

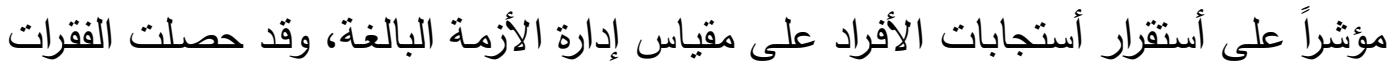
على الثبات الموضح في الجدول الآتي: أما درجة الثبات النهائية فهي عبارة عن متوسط هذه الدرجات وقدّ بلغت (0,49) وهذه

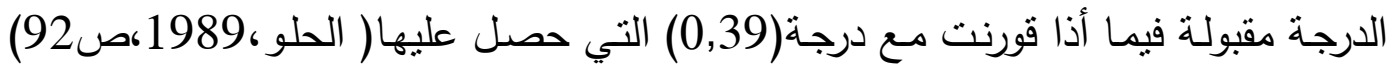

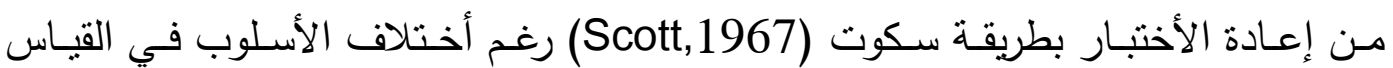

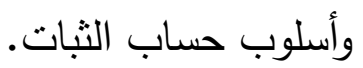

جدول معامل ثبات هولستي لفقرات مقياس إدارة الأزمة

\begin{tabular}{|c|c|c|c|}
\hline الثبات & تسلسل الفقرة & الثبات & تسلسل الفقرة \\
\hline 0,67 & 10 & 0,61 & 1 \\
\hline 0,39 & 11 & 0,50 & 2 \\
\hline 0,33 & 12 & 0,44 & 3 \\
\hline 0,33 & 13 & 0,33 & 4 \\
\hline 0,39 & 14 & 0,33 & 5 \\
\hline 0,10 & 15 & 0,72 & 6 \\
\hline 0,56 & 16 & 0,61 & 7 \\
\hline 0,72 & 17 & 0,44 & 8 \\
\hline 0,50 & 18 & 0,39 & 9 \\
\hline \multicolumn{2}{|c|}{0,49} & \multicolumn{2}{|c|}{ الكلي } \\
\hline
\end{tabular}

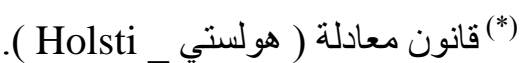
الثبات = 2*عدد المفردات المتفق عليها /عدد المفرات في التتطبيق الاول+عدد المفردات في التطبيق الثاني 
الفصل الرابع

| (النتائج وتفسيرها

(التوصيات

المقترحات

في هذا الفصل سيتم عرض وتفسير النتائج التي توصلت إليها الباحثة على وفق أهداف

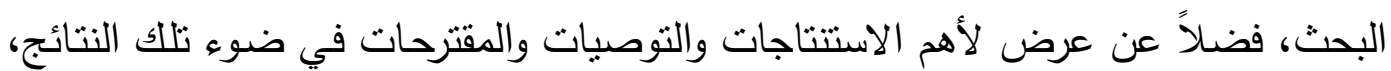
وفيما يأني عرض نتائج البحث:

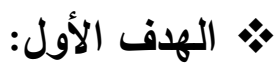

التعِرف على أسـاليب إدارة الأزمـة لدى العينة، وتحقيقاً لذلك أظهر جدول الآتي أنّ الته

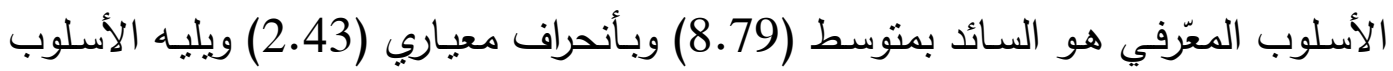
السلوكي بمنتسط (7.98) وبأنحراف معياري (2.353)، في حِّين كان الأسلوب التجنبي

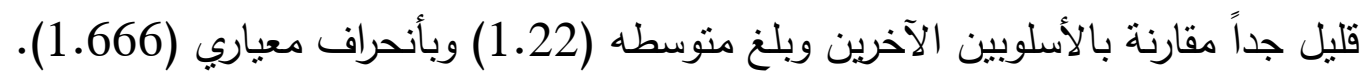
جدول المواصفات الأحصائية لأساليب إدارة الأزمة

\begin{tabular}{|c|c|c|c|c|}
\hline التباين & الانحراف المعياري & المتوسط & العدد & الأساليب \\
\hline 5.904 & 2.430 & 8.79 & 300 & المعّرفي \\
\hline 5.535 & 2.353 & 7.98 & 300 & السلوكي \\
\hline 2.776 & 1.666 & 1.22 & 300 & التجنبي \\
\hline
\end{tabular}

ويّّل هذا على إنّ المدراء لديهم أسلوبان في إدارة الأزمات وهما (المعّرفي والسلوكي)،

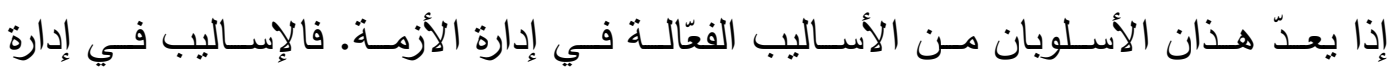

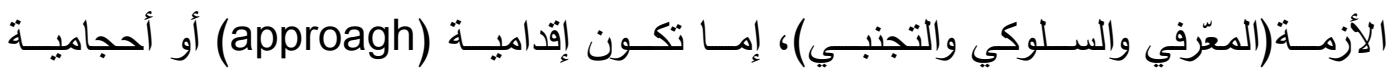

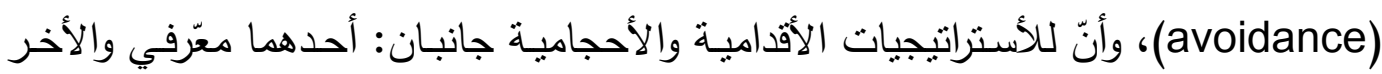
سلوكي، ولهذا يكون أسلوب الفرد وطريقته في إدارة المواقف الضـاغطة والأزمات إقدامياً

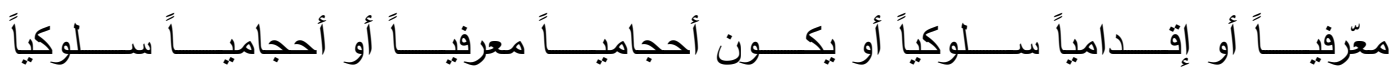

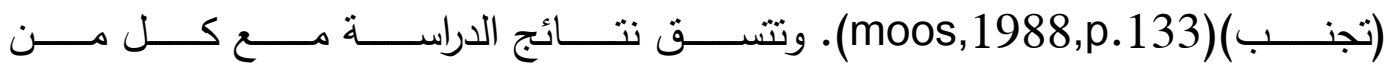

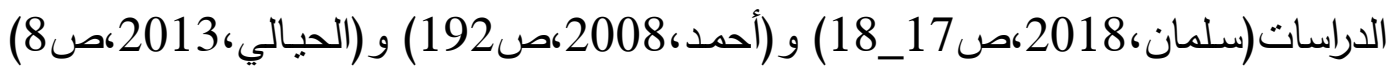

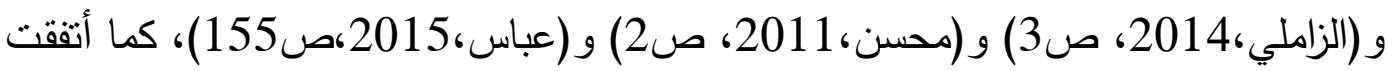

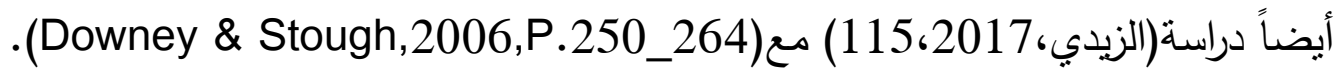




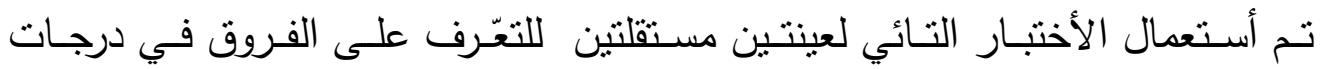
الأساليب تبعاً للتوجه المنتج وغير المنتج. إذ نثير النتيجة الى عدم وجود فرق دال إحصائياً

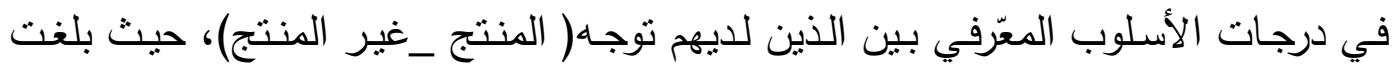
القيمة التائية(0,515) وهي أقل من الجدولية البالغة (1,98) عند مستوى (0,05) ودرجة لإنة

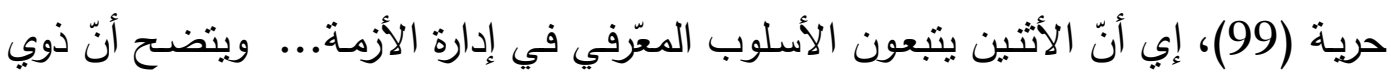

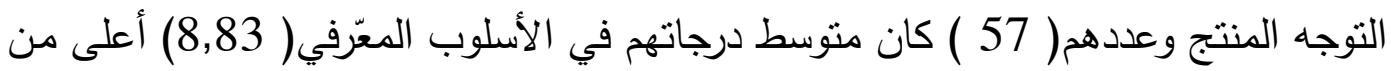

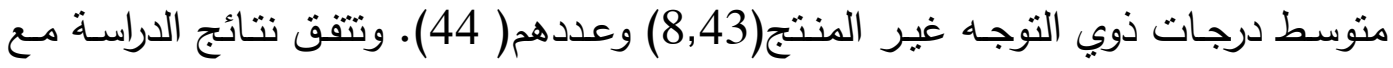
دراسة(Dickson,1982) في أسلوب تفكير المدير ودور التفكير العقلاني في إداء عمله ونه

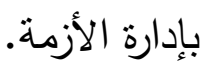

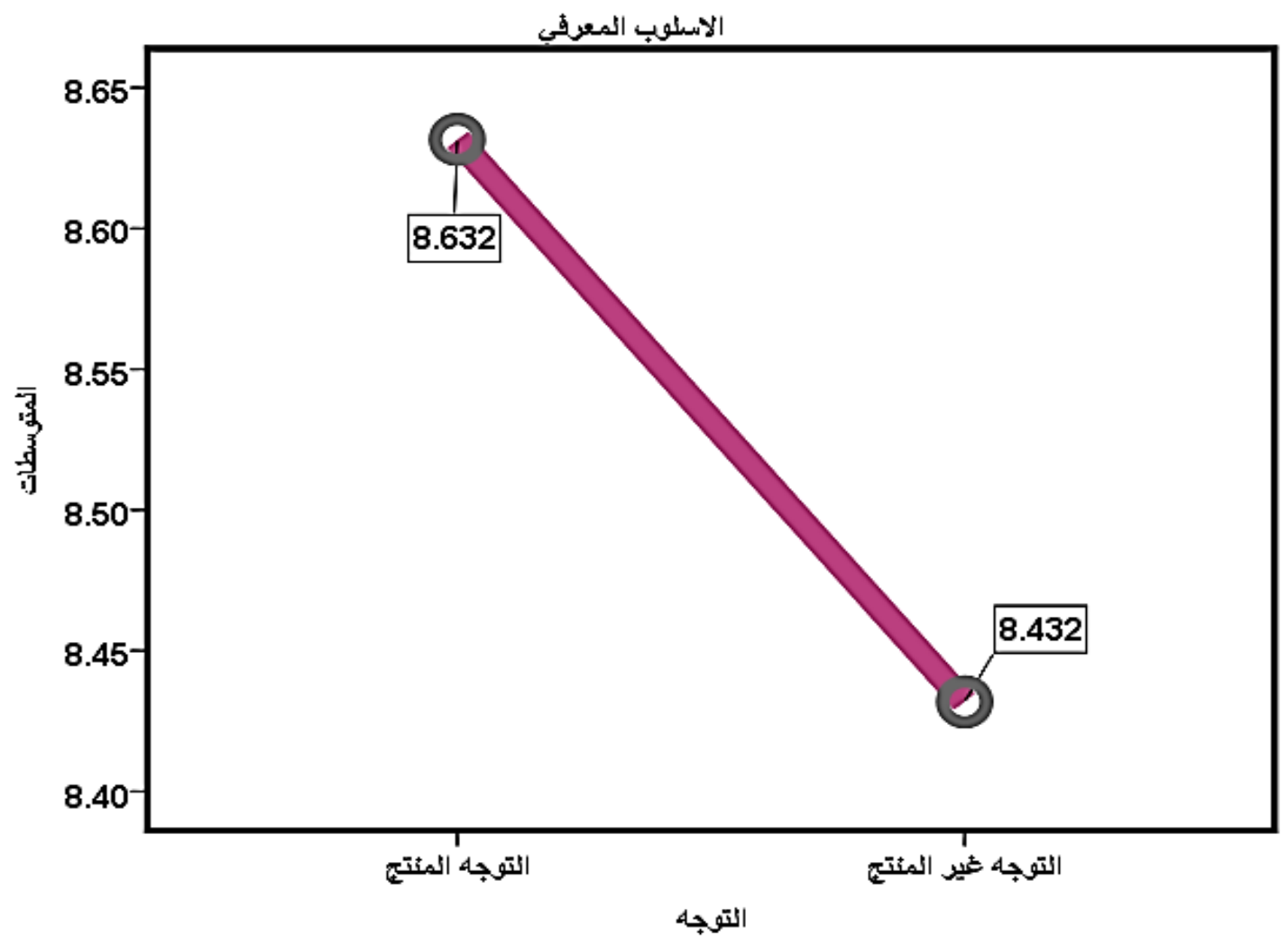

شكل لارجات الاسلوب المعرفي يوضح المتوسطات والمنحنى البياني لها

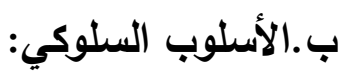

تثبير النتيجة الى وجود فرق دال إحصائياً في درجات الأسلوب السلوكي بين الذين

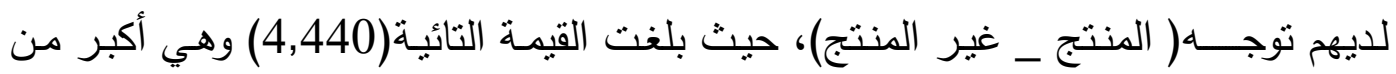
الجدولية(1,98) عند مستوى(0,05) ودرجة حرية (99) ولصالح التوجه المنتج، أب أنّ ذوي الني من 


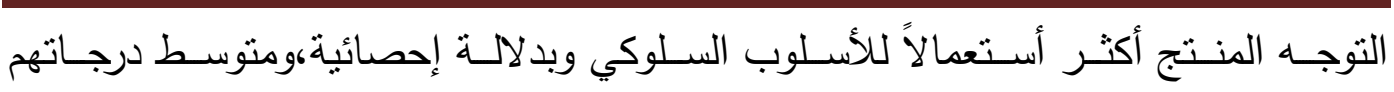
بلغي(9,09) مقارنة بذوبي التوجه غير المنتج ومتوسطهم (7,36) مـع ملاحظة أنّ الأثتين

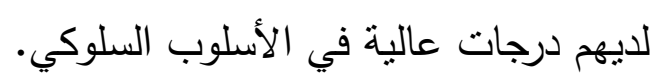

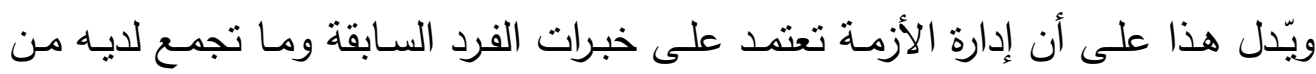

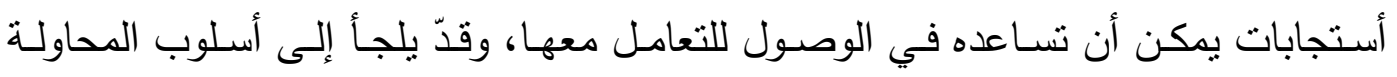

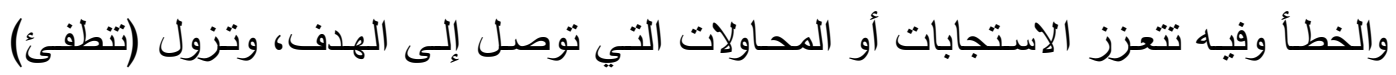

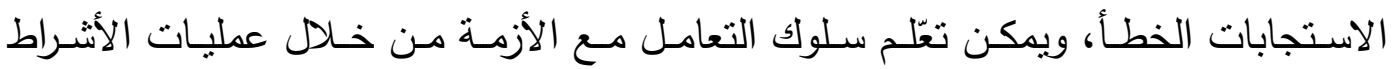

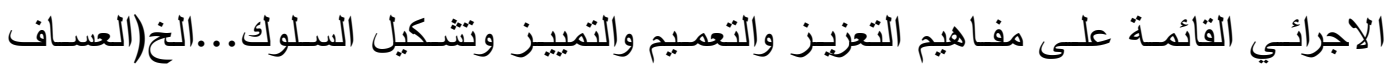

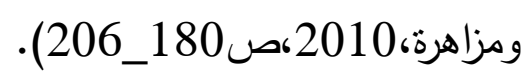

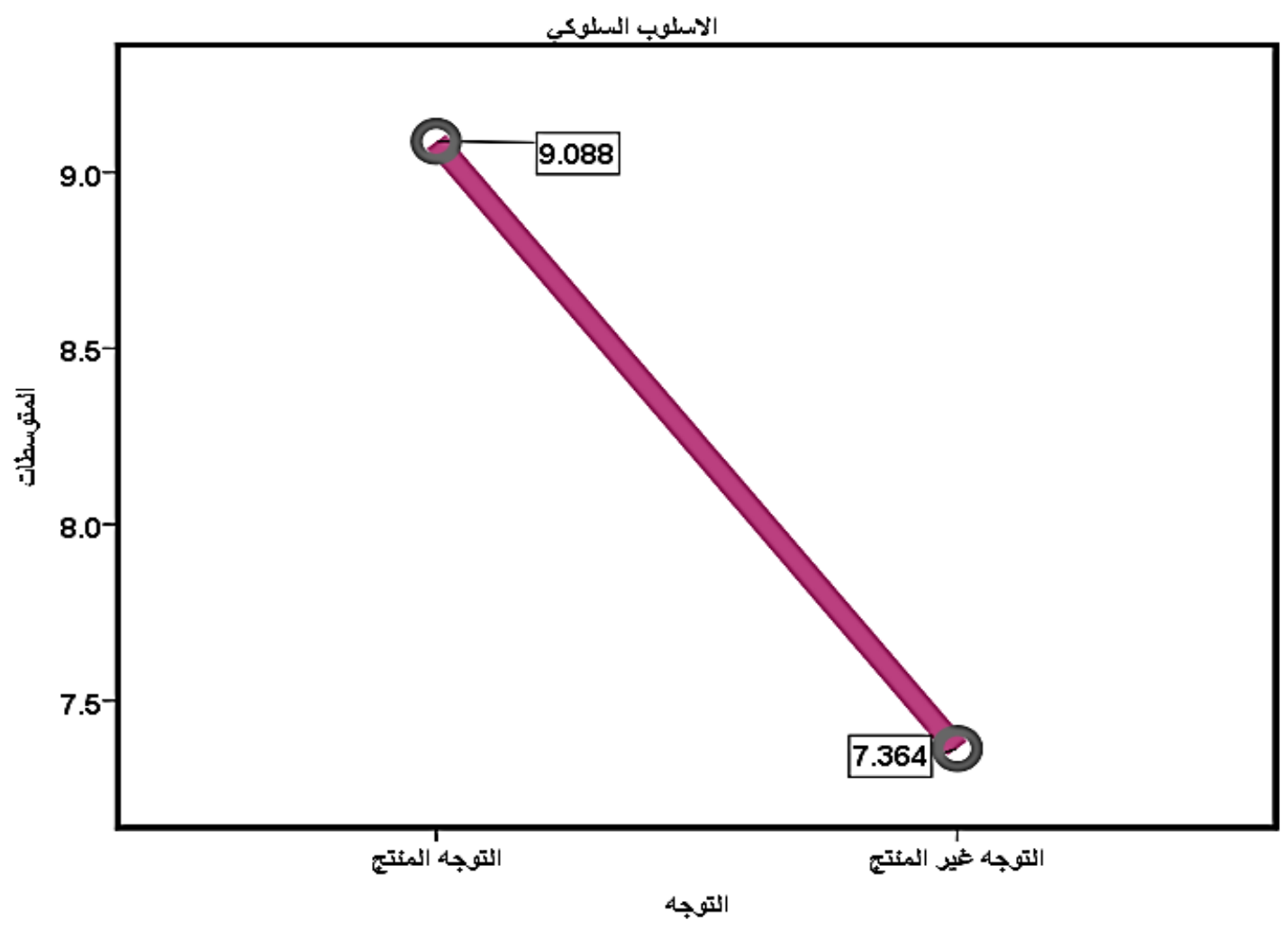

شكل لارجات الأسلوب السلوكي يوضح المتوسطات والمنحنى البياني لها

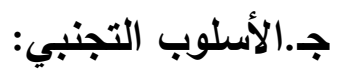

تثنير النتيجة الى وجود فرق دال إحصائياً في درجات الأسلوب التجنبي بين الذين لديهر

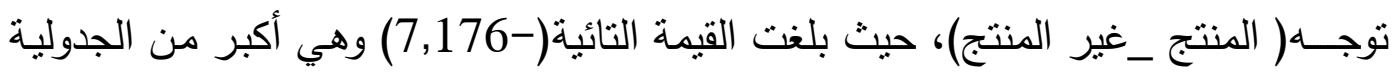

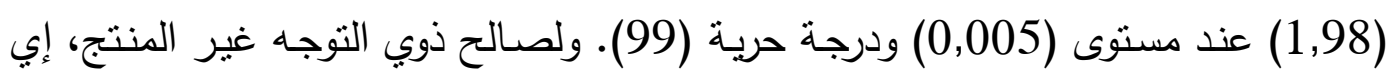

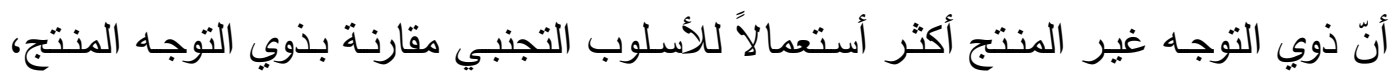

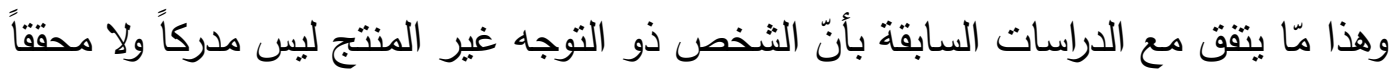

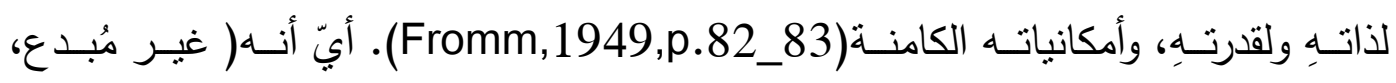




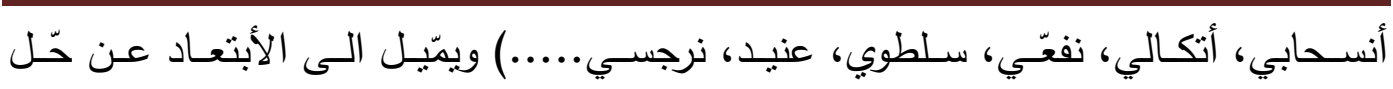

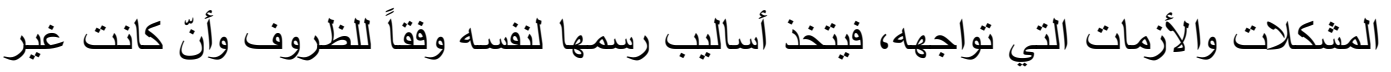
منتجة. في حِين رأى موس(Moos \& et al,1992) أن الفرد قدّ يحقق تكيفاً غير سوياً

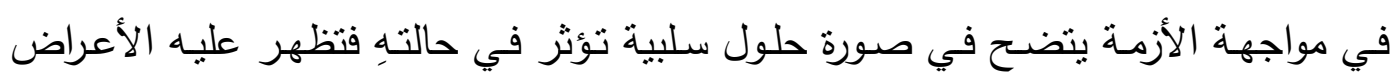

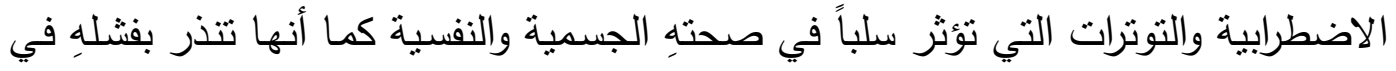

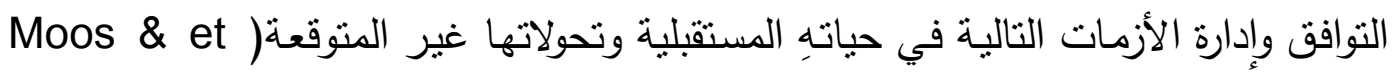

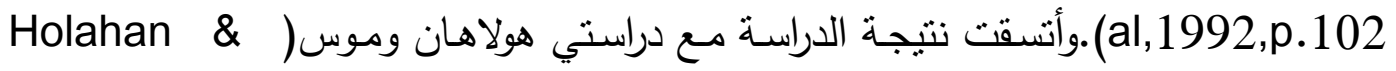
(Moos, 1986 (Ryan,1989)( وراين)

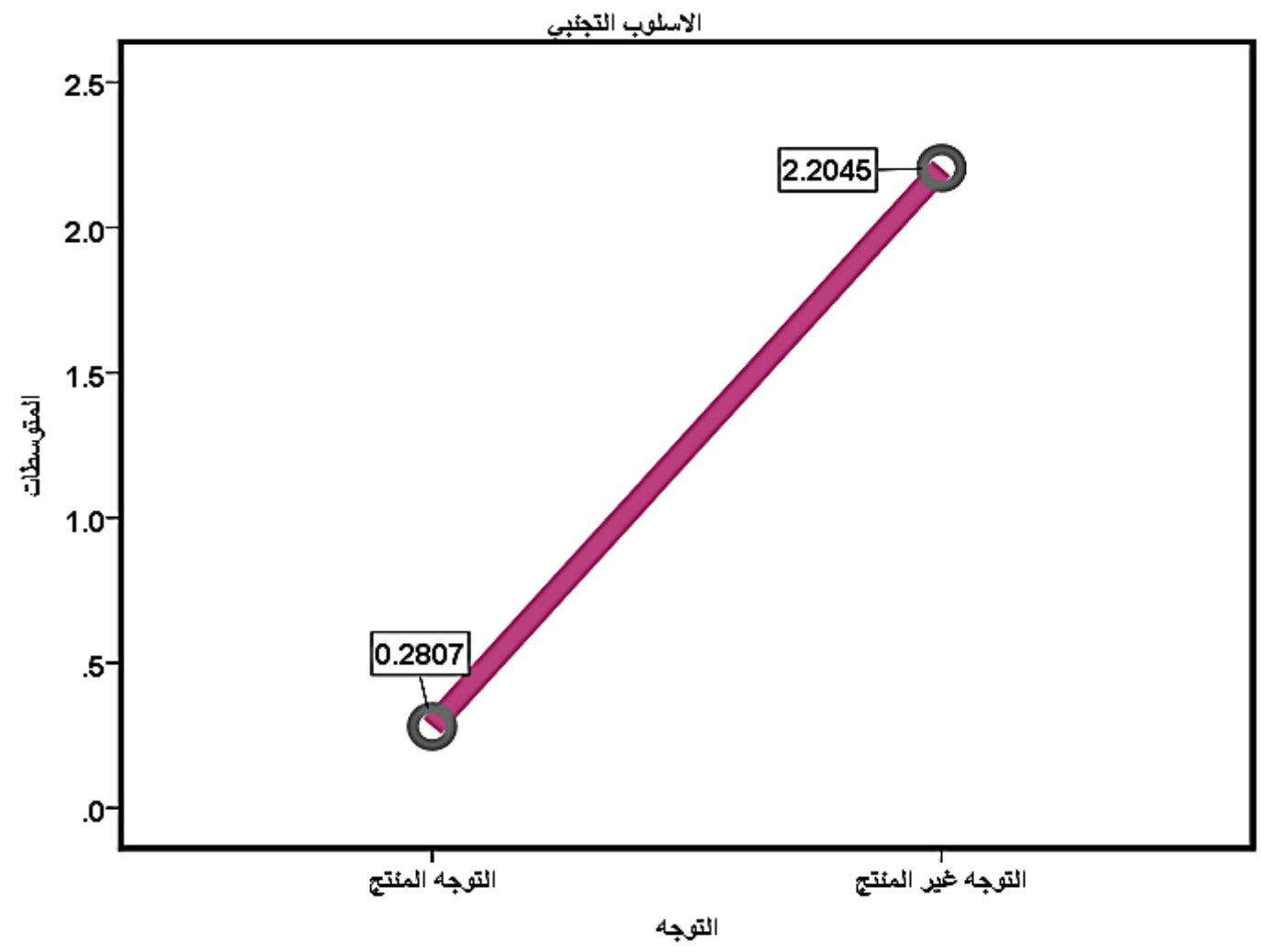

شكل لارجات الأسلوب التجنبي يوضح المتوسطات والمنحنى البياني لها

مecommendation التوصيات

بناءً على ما توصلت إليه نتائج البحث الحالي، توصي الباحثة بما يأتي:ـ

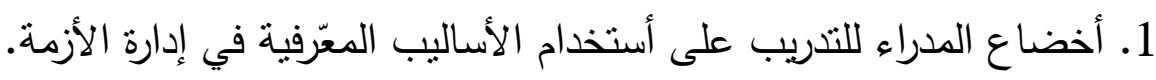

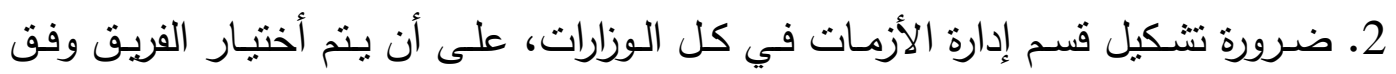
معايير محددة مسبقاً. 3.استخدام المنهج العلمي كأسلوب للتعامل مع الأزمات من قبل المدراء. 
Suggestions المقترحات

$$
\begin{aligned}
& \text { استكمالاً لنتائج البحث تقترح الباحثة الآتي:_ } \\
& \text { 1. بناء برنامج تدريبي لإدارة الأزمات للمدراء في الوزارات ومديرياتها في ضوء أحتياجاتهم } \\
& \text { النفسية والإدارية والفنية لمعالجة الأزمات الداخلية والخارجية على وفق هذا برامج. } \\
& \text { 2. تطبيق الدراسـة الحاليـة على عينـة خاصـة مـن المدراء في الدولـة كأن تكون( الدرجات } \\
& \text { الخاصة، القادة العسكربين والآمنيين، رؤوساء الهيئات). } \\
& \text { المصادر }
\end{aligned}
$$

AutgusLine , R. and William, S. (1995). The Crisis you Tried to Prevent Harvard Business Review, November.

Barron,A.(1981).Psyghology.Halt_Saunder,International edition,Japan .

C.D Spielberger and I.G. Sarason,(1979). Stress and Anxiety Volume,5,by Hemisphere Fubli-Shing Corporation .

Downey, L, Papageoriou V.\& Stough, C, (2006). Examining the Relationship between Leadership Emotional Intelligence and intuition in Senior Female Managers Leadership and organization development Jornal, volume(27), NO(4).

.Everett Susan M ,(1991). Crisis Management in school" master of education Requirements, Colorado state university .

Fink ,S ,(1986).Crisis Management :palnning for planning the Inevitable ,New York ,AMA company.P.23-34.

.Folkman,S,(1997). Meaningful events as coping with chronic stress, New York,Plenum Press.

Harrison, A,(1983).Alanguage Testing Hand Book, Mgnillan, Press, London.

Herrera, G and Alfanso, (1999). How to Manage a Crisis Before or Whenever It Hits Public Relations Quarterly, Issue.1 Vol.4, Spring. Internet.

Holahan, C. J., \& Moos, R. H, (1987a). Personal and contextual determinants of coping strategies. Journal of Personality and Social Psychology, 52, 946-955.

Holisti, Ole,(1969).Content Analysis for Social Science and Humanities, Addition, p. 12.

Jones,E.(2004). Student stress survival pack, WWW.Depression alliance.Org/Content.Student.hota1.

.Kreitner, R ,(1989). Management, New York Houghbon Mifflin company.

Kuklaa, H,(1986). Managing Crisis: Challenges and Complexities , Sam Advanced Management Journal , Autumn.

Lazarus, R,(2000). Toward better research on stress and coping Journal of Americam Psychologist , 55, 6, pp.665-673.

MC Adams , D . P and Logan , R, ( 2004 ). what is Generativity ? In ED . st . Aubin and D . P MC Adams and T . kim ( Eds ) : The Genrative society caring for future Generations , DC : APA.

Mitroff , Fan F ,(1994). Crisis management and Enivonment talism : A Natural fit , California management Review , No. 3 winter.

Moss, R .H,(1986). Life transitions and crises A conceptual over view, in Rudolf H .Moos ( Ed) coping with Life criss ,New York, plenum press.

Moss, R. Tsehacfer ,(1986). J life transitions and crises: Aconceptu loverie W. inr. H. Moos (Ed), coping with lifcrises:an integeate Approach New York .

Moss,R \& Schafer,J,(1986). Coping with life crises,new York plenum press. 
,(1987). Determinates of coping strategies Holahan personal and .cotextual . a social psychology .52 (2) pp.945-955.

,(1988). Life stressors and coping resources influence health and well being",Psychological Assessment,Vol,4 .

(1990) coping Resources and processes ; current concepts and

Measures . InL, Goldberger and S. breznitz (E ds) Hand book of coping with Life criss ,New York, plenum press.

Nitroof I.I,(2001).Managing Corporate Crisis' ,Book Review Vol. ,No.3,Internet.

Nunnally ,j . c,(1978). psychometric theory, new York 2th ed mac crow - hill.

Orifici , J .Michael ,(2000).Developing an Effective Crisis Management Plan :The Role of a Project Manager : School

Business Affairs, vol (66),no (9).sep.

Ryan, N, (1989). "stress-coping strategies identified from school age childrenspcrspective " Research in Nursing and Health,vot,12,N.(2).

Stanley G.J \& Hopkins,K.D,(1972). Educational and Psychology measurement evaluation, prentice-hall,New Jersey. 


\section{Abstract}

As for the concept of crisis management, the researcher prepared a measure for it, based on the theory of Moss, which he defined: "It is the employment of the individual to his adaptive strategies with the stressful situation in order to restore his psychological and social equilibrium" (Moss, 1990, p. 234), as well. On asking an exploratory question to the sample, (18) situations expressing the crisis experienced by the directors in their departments, and each situation has three methods to deal with it (cognitive, behavior, and avoidance).

The researcher has verified the validity of its measurement with two indicators, which are validity by presenting the paragraphs of the scale with a questionnaire on (14) arbitrators in psychological measurement and psychology, and based on their opinions the paragraphs of the scale have been modified, and the indicator of the reliability through the correlation of the degree of the paragraph with the overall degree, and the correlation of the degree of the paragraph with the behavioral component To which it belongs, and the researcher has verified the stability of the scale by a re-test method, with an average (0.49) of the crisis management scale.

After verifying the accuracy of the psychometric properties of the research tools and their paragraphs, the research tools were applied to the basic research sample of (300) director, and the data were analyzed using the statistical bag of social sciences (spss) and the results showed the following:

1. managers follow two methods of crisis management, namely (cognitive and behavioral) compared to the (avoidance) method.

2. Productive-oriented managers follow the cognitive and behavioral approaches to crisis management. 